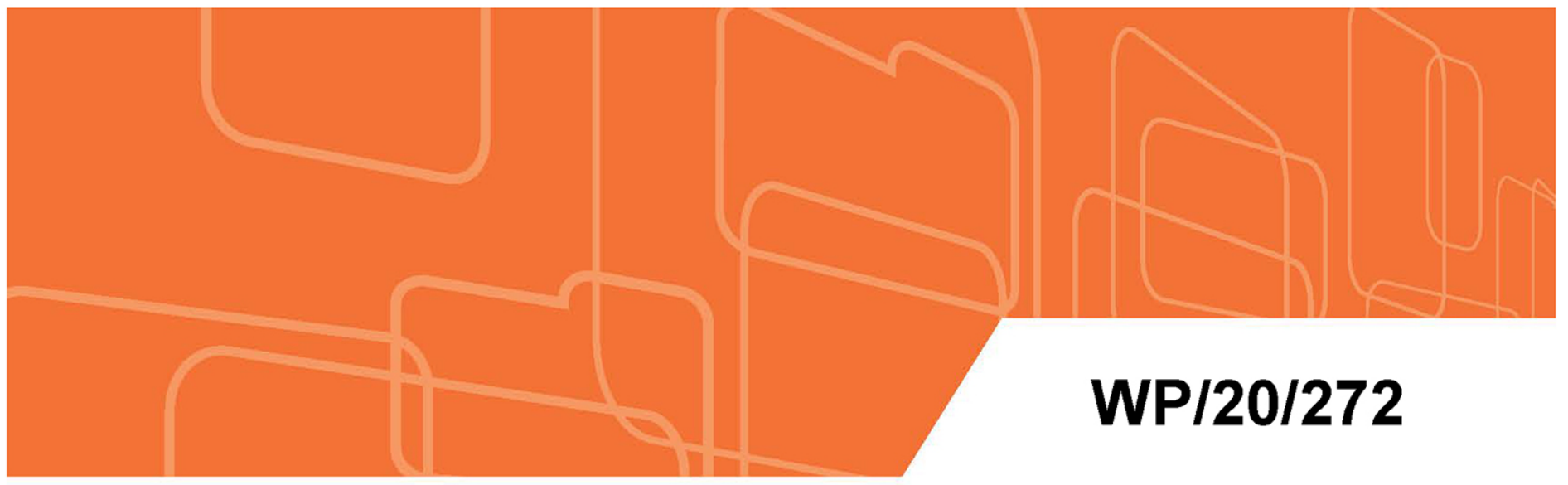

\title{
Addressing the Pandemic's Medium-Term Fallout in Australia and New Zealand
}

by Geoffrey Bannister, Harald Finger, Yosuke Kido,
Siddharth Kothari, and Elena Loukoianova

IMF Working Papers describe research in progress by the author(s) and are published to elicit comments and to encourage debate. The views expressed in IMF Working Papers are those of the author(s) and do not necessarily represent the views of the IMF, its Executive Board, or IMF management. 


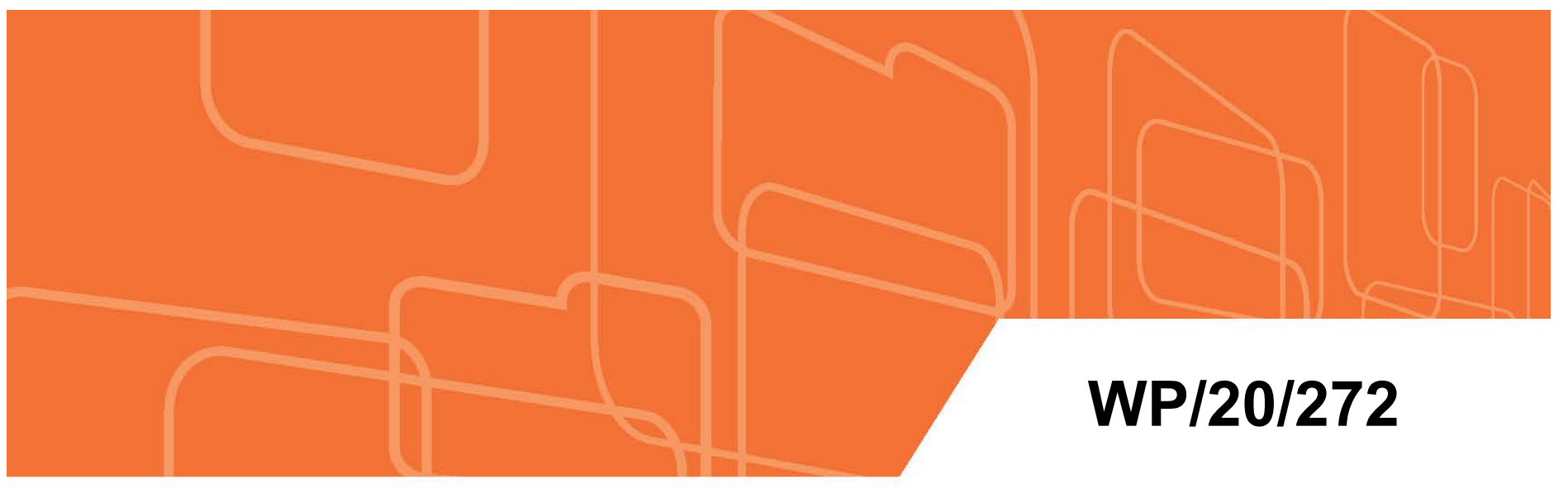

\section{IMF Working Paper}

\section{Addressing the Pandemic's Medium-Term Fallout in Australia and New Zealand}

by Geoffrey Bannister, Harald Finger, Yosuke Kido,

Siddharth Kothari, and Elena Loukoianova

IMF Working Papers describe research in progress by the author(s) and are published to elicit comments and to encourage debate. The views expressed in IMF Working Papers are those of the author(s) and do not necessarily represent the views of the IMF, its Executive Board, or IMF management.

I N T E R N A T I O N A L M O N E T A R Y F U N D 


\title{
IMF Working Paper
}

Asia and Pacific Department

\section{Addressing the Pandemic's Medium-Term Fallout in Australia and New Zealand \\ Prepared by Geoffrey Bannister, Harald Finger, Yosuke Kido, Siddharth Kothari, and Elena Loukoianova ${ }^{1}$}

Authorized for distribution by Harald Finger

December 2020

IMF Working Papers describe research in progress by the author(s) and are published to elicit comments and to encourage debate. The views expressed in IMF Working Papers are those of the author(s) and do not necessarily represent the views of the IMF, its Executive Board, or IMF management.

\begin{abstract}
While the world is focused on addressing the near-term ramifications of the COVID-19 shock, we turn attention to another important aspect of the pandemic: its fallout on mediumterm potential output through scarring. Taking Australia and New Zealand as examples, we show that the pandemic will likely have a large and persistent impact on potential output, broadly in line with the experience of advanced economies from past recessions. The impact is driven by employment, capital stock, and productivity losses in the wake of an unprecedented sectoral reallocation, hightened uncertainty, and reduced migration. Maintaining fiscal and monetary policy support until the recovery is firmly entrenched and putting in place a strong structural policy agenda to counter the pandemic's adverse effects on medium-term potential output will be important to support standards of living and strengthen economic resilience in case of renewed shocks.
\end{abstract}

JEL Classification Numbers: E20, O40, O47, O56

Keywords: Potential output, scarring, COVID-19, advanced economies, Australia, New Zealand

Author’s E-Mail Addresses: gbannister@imf.org; hfinger@imf.org; ykido@imf.org; skothari@imf.org; eloukoianova@imf.org

\footnotetext{
${ }^{1}$ The authors are grateful for helpful discussions with, and input from, Davide Furceri, Angelia Grant, Deniz Igan, Nigel Ray, Brian Walker, and Fan Zhang. The paper also incorporates helpful comments received from staff of the Australian Treasury, Reserve Bank of Australia, New Zealand Treasury, and IMF staff, including in several webinars. Ioana Hussiada and Nadine Dubost provided excellent support in the production of this paper.
} 


\section{INTRODUCTION}

There is growing recognition that the COVID-19 pandemic may have long-lasting negative effects on the economy. The COVID-19 pandemic has exacted a heavy human toll and triggered the worst global recession since the Great Depression. While a near-term recovery supported by reopening of the economy following lockdowns has set in, this recovery may turn out to be drawn-out and partial given the pandemic's longer-term economic impact through scarring. ${ }^{2}$

Focusing on Australia and New Zealand as examples among advanced economies, this paper estimates the impact of the COVID-19 crisis on potential output in the mediumterm, disentangling the different channels (employment, capital stock, and productivity) through which these effects may take place. Australia and New Zealand were chosen because (i) both countries have strong institutions and the needed policy space to preemptively implement policies that can limit the medium-term effects of the pandemic, thus making an early assessment of the channels of scarring invaluable; and (ii) their examples show that the pandemic can significantly affect medium-term output even in countries with strong health and economic policy responses.

\section{Medium-term potential output in Australia and New Zealand will likely be significantly} below pre-COVID-19 trends, putting a premium on strong economic policies to mitigate this impact. Our analysis suggests that, by 2025, potential output in Australia and New Zealand may remain around 3-8 percent below the trend projected prior to the pandemic, broadly in line with experience from previous recessions in advanced economies. ${ }^{3}$ This reflects a confluence of factors, including skills mismatches in the context of a significant sectoral reallocation, impaired immigration due to border closures and the effects of COVID-19 on source countries, and lower total factor productivity growth and capital accumulation given expected balance sheet impacts on firms and heightened uncertainty. The anticipation of a sizable medium-term output loss underscores the significance of supportive policies, both to limit the initial output losses - thereby minimizing the potential for scarring - and to mitigate the negative impact on medium-term potential output through supply side policies.

\footnotetext{
${ }^{2}$ Throughout the paper, scarring effects refer to the negative impact of the crisis on medium-term potential output, acting through various channels discussed below.

${ }^{3}$ It should be noted that uncertainty to these projections is high as our analysis relies largely on data to $2020 \mathrm{Q} 2$ or July 2020.
} 
The paper is structured as follows. Section II gives a brief overview of the literature on medium-term economic effects of recessions in advanced economies. Section III provides cross-country evidence from past recessions in advanced economies to provide a first reference point on what may be expected in the current context. This helps to put the medium-term economic growth analysis for Australia and New Zealand in Section IV into a global prospective. Based on the results of this analysis, the paper provides policy implications and conclusions in Section V.

\section{LITERATURE REVIEW}

While the current global recession is undoubtedly unique in its characteristics, the large literature on the effects of recessions can nonetheless provide a useful reference point. Recessions have been rare in Australia and New Zealand over the past 30 years, prompting us to look at the broader literature on recessions in advanced economies. ${ }^{4}$ A significant share of that literature focuses on the global financial crisis (GFC), with very different triggers and characteristics from the current global recession. But a number of studies also take a longer historical view, looking at broader samples. While the recessions studied all featured their individual characteristics different form the current episode, an aggregate view provides a useful overview on common effects, a useful first yardstick in exploring the current recession.

Several authors have noted that recessions have a persistent effect on actual output and employment. Cerra and Saxena (2008) find that, across a large sample of countries, the output loss associated with financial and political crises is large and highly persistent. Similarly, Abiad et al. (2009) conclude that output remains permanently below pre-crisis trends after a financial crisis, and Bluedorn and Leigh (2018) find that forecasters consider the permanent, negative effects of crises in projections for future output. Pisani and van Pottelsberge (2009) discuss the persistent impact of banking crises on output using case studies. These studies indicate that recessions also have a large and persistent effect on potential output, defined as the level of output at which the economy is operating at maximum sustainable employment, with unemployment at its natural rate.

\section{The impact of the GFC and other recessions on potential output has been studied} widely. ${ }^{5}$ Most studies rely on a growth accounting framework, variants of the best-practice

\footnotetext{
${ }^{4}$ Similarly, there are few studies of potential output in Australia and New Zealand. Two useful references are de Brouwer (1998) and Lienert and Gillmore (2015). Arsov and Watson (2019) review potential growth in advanced economies.

${ }^{5}$ See Ball (2014), Benati (2012), Celik, Kose, and Ohnsorge (2020), Fernald (2015), Hallaeert et al. (2013), IMF (2009, 2013a, 2013b, and 2015), and Martin, Munyan, and Wilson (2015) among others.
} 
frontier approach, vector autoregression models, various filtering models, or structural time series forecasting to calculate effects of a recession or crisis on potential output. ${ }^{6}$ Furceri and Mourougane (2012) apply the Cerra-Saxena (2008) approach (using an autoregressive model of output growth rates augmented by crisis dummies) to growth rates of potential output in OECD countries and find a sizable impact. Several studies for individual countries also find lower potential growth after the GFC, ${ }^{7}$ attributing it to various factors, such as tighter financial conditions, inadequate institutions and policy responses, as well as fading demographic dividends. Dovern and Zuber (2020) show that downward revisions of potential output after recessions are substantial, permanent, and mostly driven by supply shocks. Alichi et al. (2019) indicate that hysteresis generates much larger movements in the NAIRU and potential output in the United States. Overall, studies estimate the level of output after the GFC and other recessions to be between 4 and 9 percent below the pre-crisis output trend, and annual growth of potential output to be between 0.5 percent and 3 percent below precrisis trends about five years after the crisis (Table 1).

Table 1 - Effect of the GFC and Other Recessions on Potential Output Growth (percent, or percentage points)

\begin{tabular}{llccc}
\hline \multicolumn{1}{c}{ Publication } & \multicolumn{1}{c}{ Countries } & Time Period & PO growth relative to pre-crisis trend & PO level percent of pre-crisis trend \\
\hline Dovern and Zuber (2020) & OECD & $1990-2017$ & -- & -4.1 \\
Furceri and Mourougane (2012) & OECD & $1960-2008$ & -1.5 & --- \\
Martin et al. (2015) & UK, EU, US, CAN & $2000-14$ & -- & US -8.2, UK -9.5, EU -7.8, CAN -6.0 \\
Alichi et al. (2019) & U.S. & $2007-18$ & -0.5 & --- \\
Ball (2014) & OECD & $2007-14$ & -1.2 & -8.4 \\
Barrera et al (2009) & US & $2009-14$ & -0.9 & -5.8 \\
Benati (2012) & UK, EU, US, JPN & $2007-11$ & UK -3.7, EU -0.9, US -1.3, JPN -0.4 & --- \\
Benes et al. (2013) & France & $2008-12$ & -1.2 & -4.0 \\
Celik et al. (2020) & Advanced Economies & $2013-17$ & -0.5 & --- \\
IMF (2015) & Advanced Economies & $2008-14$ & -0.5 & -6.5 \\
\hline
\end{tabular}

\section{Several studies analyze the sectoral reallocation of employment and its nexus with labor productivity, business cycles and aggregate employment. ${ }^{8}$ The re-allocation of labor} across sectors during recessions is found to be a determinant of labor supply affecting potential output in almost all of those studies. Campbell and Kuttner (1996) conclude that reallocation shocks account for the majority of the variance in employment shares and their

\footnotetext{
${ }^{6}$ Alichi et al. (2015).

${ }^{7}$ Including for the United States (IMF, 2009, and Fernald, 2015, Grant and Chan, 2017), France (Hallaert et al., 2013), Portugal (IMF, 2013a), and Brazil (2013b).

${ }^{8}$ Duarter and Restuccia (2010), Campbell and Kuttner (1996), Valetta and Cleary (2008), Tase (2019), Aarson, Rissman, and Sullivan (2004), Ngai and Pissarides (2007), David and Haltiwanger (1999), Hobijn and Sahn (2013), Goshen and Potter (2003), and ElFayoumi, Ndoye, Nadeem, and Auclair (2018).
} 
dispersion. Chodorow-Reich and Wieland (2020) provide evidence of reallocation contributing to higher local area unemployment, if it occurs during a national recession but little difference in outcomes during an expansion, i.e. the consequences of reallocation depend on the phase of the business cycle. Meehan (2014) analyzes the contribution of sectoral reallocation to labor productivity growth in OECD countries over 1990-2005 and finds that the effect was -0.1 percentage point per year on average across countries $(-0.4$ percentage point for New Zealand).

\section{Sectoral reallocation is correlated with recessionary periods, in particular during the}

GFC (Valetta and Cleary, 2008). Tase (2019) presents an index of sectoral changes and finds that structural change is concentrated in recessions and has changed over time, falling since the 1990s. Similarly, Aaronson, Rissman, and Sullivan (2004) and Goshen and Potter (2003) examine the labor market after the 2001-02 recession in the United States and find that reallocation of employment across industries declined over the two business cycles previous to the 2002 recession. Bart and Sahin (2013) measure the Beveridge curve (relationship between unemployment and the job vacancy rate) and find that the displacement of a large part of the labor force during deep recessions results in a shift of the composition of vacancies and an increase in mismatch in the labor market. Using a cross-country panel regression analysis, El Fayoumi et al. (2018) explain structural reallocation of labor across sectors as a function of the labor productivity gap and show how the speed of reallocation can contribute to the growth of output. In a more general setting, analyzing postwar data on U.S. manufacturing, Davis and Haltiwanger (1999) show that the labor market reallocation process plays an important role in cyclical employment fluctuations.

\section{Other strands of the literature focus on the contribution of lower productivity growth} and investment on post-recession potential output. Adler et al. (2017) cite the persistent total factor productivity (TFP) loss ("TFP hysteresis") resulting from the global financial crisis and previous recessions, and attribute the decline to three interrelated factors: weak corporate balance sheets and credit constraints, which reduce investment in new technologies and result in capital misallocation; weak aggregate demand that reduces incentives to invest in capital-embodied technological change; and policy uncertainty that further tilts investment away from innovation-intensive higher-risk and higher-return projects. Hennessy (2004) incorporates debt into a dynamic real options framework and finds that the negative effect of debt overhang (as could result from recessions) on investment is significant. Bernanke (1983) 
lays the foundation for the study of the negative effects of uncertainty on investment, with more recent contributions including Bloom (2009) and Bloom et al. (2007). ${ }^{9}$

\section{The latest strand of literature focuses on the impact of the COVID-19 shock and} sectoral reallocation. IMF (2020a and 2020b) and Deb et al. (2020) find that short-term economic costs related to the pandemic are high, especially in sectors that are face-to-face contact-intensive and for workers (mainly low-income, women and youth) in these sectors, implying a need for policies to facilitate sectoral reallocation. Barrero, Bloom, and Davis (2020) construct novel, forward-looking reallocation measures for jobs and sales and find that these measures rose sharply after February 2020, more than twice compared with the pre-COVID average for jobs and close to four times for sales. David (2020) finds that the inter-industry reallocation in the United States caused by the COVID-19 pandemic may have a significant and persistent determinantal effect on the aggregate unemployment rate, with the peak impact occurring after 24 months. Angelini et al. (2020) find different economic effects from various confinement measures, which could eventually affect potential output through lasting labor market disruptions, heightened uncertainty and adverse financial market developments.

\section{Previous studies have found that the impact of lower potential output and labor market reallocation could be mitigated by appropriate economic policies. ${ }^{10}$ For example, a gradual alignment of product market regulations to best practice in a broad range of non- manufacturing sectors could boost labor productivity. More generally, on average, a range of reforms in different sectors and the regulatory environment might boost overall potential GDP in OECD countries by 10 percent over a 10-year horizon (Bouis and Duval, 2011). ${ }^{11}$ Reforms should aim at increasing competition, improving the regulatory environment, and boosting competitiveness.}

\section{Cross-Country Evidence}

We analyze the experience of advanced economies in past recessions to provide some historical context on the possible medium-term effects of the current crisis. We examine whether GDP losses during recessions are permanent or whether the output losses are

\footnotetext{
${ }^{9}$ Related to this, Kozlowski et al (2020) find that scarring of belief, a persistent change in the perceived probability of extreme, negative shocks in the future, would reduce investment and output in the long run. ${ }^{10}$ For example, Ostry et al. (2009), Mitra et al. (2016), Bouis and Duval (2011), Bouis, Duval, and Eugster (2016), and Bourles et al. (2013).

11 The impact ranges from 1 percent to nearly 20 percent. Estimated impacts for Australia and New Zealand are lower than the OECD average as both countries have relatively good institutions.
} 
recouped after the end of the recession. In addition, the medium-term dynamics of the components of GDP (labor, capital stock, and productivity) are also studied. The current crisis - characterized by a large initial supply shock due to containment measures, unique uncertainty surrounding the path of the pandemic, and unprecedented restrictions on international travel - is arguably different from most previous recessions. Nevertheless, the broad cross-country evidence discussed here can provide a useful benchmark. Furthermore, the granular analysis of the components of GDP helps inform some of the medium-term projections considered in the next section.

The local projection method is used to study the deviation of output and its components from pre-recession trends. Our baseline sample consists of 23 advanced economies for which recession start dates are identified in Martin et al. (2015). Data on GDP, employment, capital stock and productivity are from Penn World Table 9.1, while the breakdown of employment into unemployment rate and participation rate is taken from the OECD (see Appendix 1 for details on the methodology). Our sample covers the period from 1970 to 2017.

Past recessions in advanced economies have had long lasting effects. Figure 1 shows the impulse response function of GDP following a recession. On average, GDP was about 43/4 percent below trend three years after the start of a recession. After the third year, the impulse response flattens out, indicating that the growth rate of GDP returns to pre-recession values, though the level of GDP remains below trend in the medium-term.

The persistent medium-term effects were driven by large recessions. Figure 2 shows the dynamic response of GDP after recessions, distinguishing between large and other recessions. Large recessions are defined as recessions where the peak to trough decline in GDP was in the top quartile of all recessions in the sample, which translates to a fall of 4.25 percent or more. Recessions in the bottom three quartiles in terms of the peak to trough decline in GDP are classified as other recessions. ${ }^{12}$ GDP continues falling below trend for several years after large recessions and is about 11 percent below trend in the medium term. In contrast, for other recessions, output is about 2.5 percent below trend two years after the start of a recession, but there is catch up growth after that, with GDP not being significantly below trend by the fifth year.

\footnotetext{
${ }^{12}$ In Australia and New Zealand, the decline in GDP in 2020Q2 relative to peak was 7.2 and 13.4 percent, respectively, well above the threshold for a large recession.
} 
Figure 1: Recessions Have a Marked Medium-Term Impact (deviation of GDP from trend, percent)

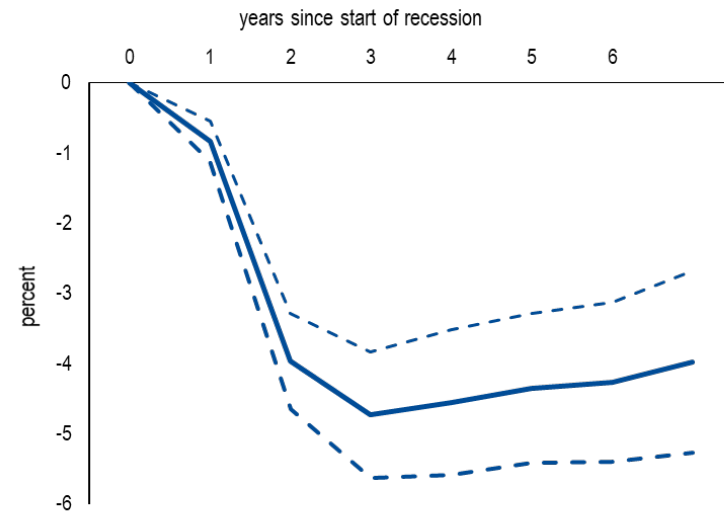

Source: PWT, IMF staff calculations.

Notes: Impulse response functions based on local projection method. Sample consists of 23 countries from 1970 to 2012 . Recession definition taken from Martin et al (2015). Dashed lines show the 90 percent confidenceinterval.
Figure 2: Medium-Term Effects of Recessions Are Driven by Large Recessions

(deviation of GDP from trend, percent)

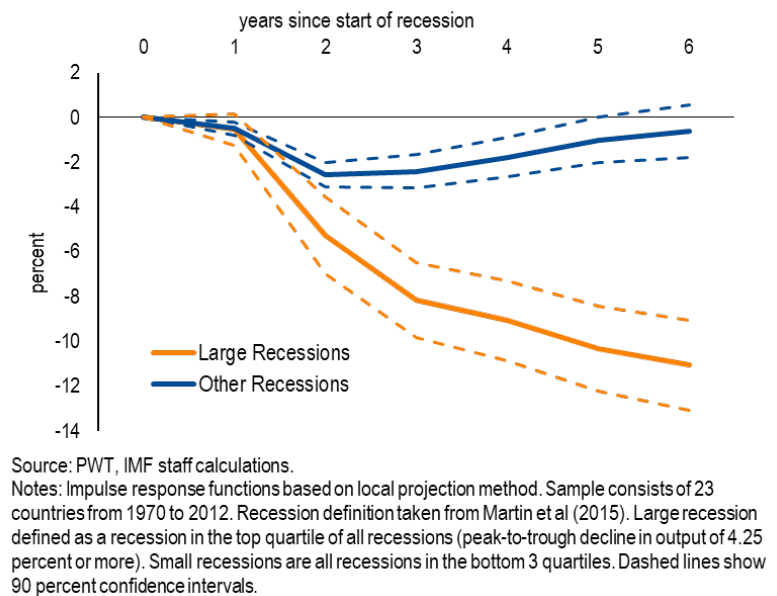

\section{The long-lasting effects of recessions are due to significant declines in the growth of} productivity and the capital stock, along with a persistent increase in unemployment.

Figure 3 shows the deviation of various components of output from pre-recession trends 5 years after the start of a recessions. For large recessions (Figure 3, left panel), TFP is almost 6 percent below trend. The capital stock is about 7 percent below trend, driven by a significant decline in investment as a share of GDP, which remains about 1.5 percentage points below pre-recession levels in the medium term. The decline in employment is driven by an increase in the unemployment rate by about 3.5 percentage points, whereas there is no significant change in labor force participation. The limited average effect on labor force participation is due to significant heterogeneity in responses across different recessions, with some episodes being associated with a decline in participation (potentially reflecting scarring) while others being associated with an increase (possibly reflecting greater incentives to work). Results are similar when considering all recessions (Figure 3, right panel), though are quantitatively smaller. 
Figure 3: Productivity, Capital Stock, and Employment Decline after Recessions (deviation from pre-recession trend after 5 years, percent change)

Large Recessions

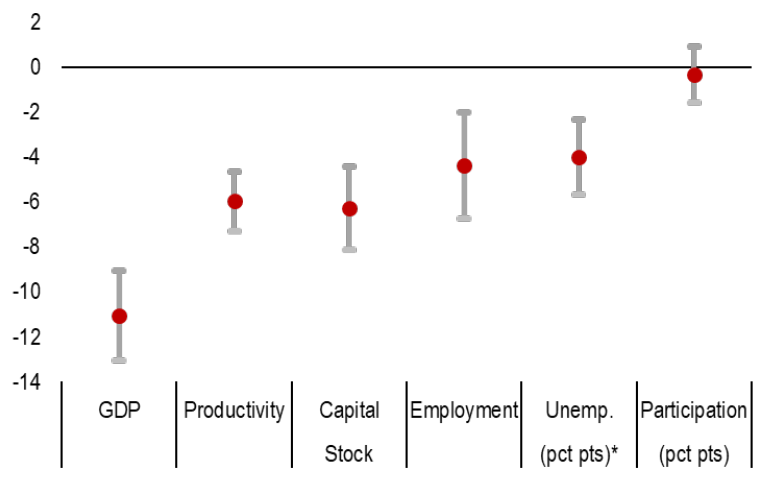

All Recessions

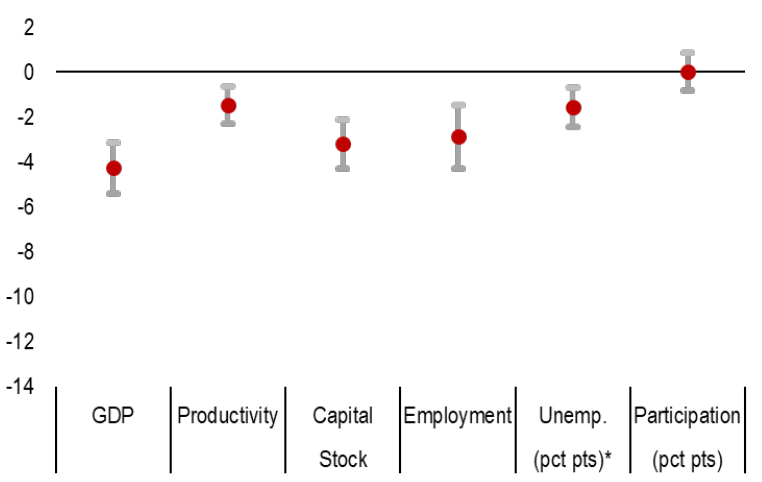

Source: PWT, OECD, IMF staff calculations.

* Scale reversed.

Notes: Dots show the coefficient estimate while gray lines show the 90 percent confidence interval. "Productivity" denotes total factor productivty, "Unemp" is the unemployment rate, "Participation" is the labor force participation rate. Plotted values show percentage points deviation for the unemeployment and participation rates. Estimates based on local projection method. Recession definition taken from Martin et al (2015). Large recession defined as a recession in the top quartile of all recessions (peak-to-trough decline in output of 4.25 percent).

\section{The result that large recessions have}

\section{persistent medium-term effects on}

\section{GDP is robust to changes in}

\section{specification and sample selection}

(Figure 4). A large literature shows significant scarring effects from financial crises, which were present in about 40 percent of the large recessions in the sample. Limiting the sample to large recessions that were not accompanied by banking or currency crises, or excluding the period of the global financial crisis, reduces the estimate for the mediumterm impact on GDP from over
Figure 4: Persistent Effects of Large Recessions Is Robust Across Specifications

(deviation from pre-recession trend after 5 years, percent)

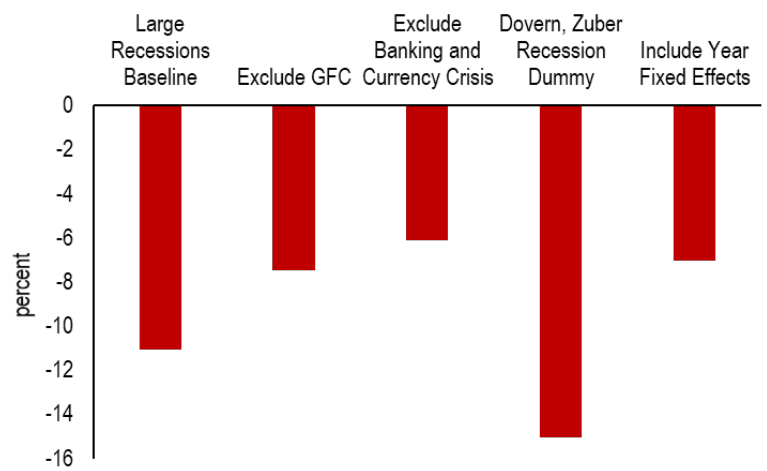

Source: PWT, IMF staff calculations.

Notes: Estimates based on local projection method. First bar repeat the baseline resultfrom Figure 2. Second bar exludes all recessions after 2006. Third bars excludes all recessions which were accomponied by a bankig or currency crisis as identified by Laeven and Valencia (2018). Fourth bar uses an alternate definition of recessions based on Dovern and Zuber (2020) which has alarger country coverage $(27$ countries) but a shorter time coverage (1990 to 2017). Fifth bar includes year fixed effects in the local projection model. All coefficients are statistically different from 0 at 95 percent confidence intervals.

11 percent to about 6 percent. The impact remains significantly different from zero, indicating that non-financial crises, like the one many countries are facing now, can also result in significant scarring. ${ }^{13}$ Results are also robust to using an alternate definition of

\footnotetext{
${ }^{13}$ Banking and financial crises are based on Laeven and Valencia (2018). Recessions which had a banking or currency crisis in the same year, or the year before or after the start of the recession, are excluded in the robustness check.
} 
recession (as identified by Dovern and Zuber, 2020) that covers more countries but over a shorter period, as well as including year fixed effects in the local projection model. ${ }^{14}$

\section{Prospects for Medium-term Potential OutPut in Australia ANd NeW ZEALAND}

\section{A. POTENTIAL OUTPUT BEFORE THE PANDEMIC}

\section{Potential output in Australia and New Zealand before the pandemic is analyzed using a} semi-structural multivariate filter model. The model incorporates a Phillips curve and Okun's law, thereby identifying unobservable economic slack and underlying potential output from observed data on output, inflation and the unemployment rate (Blagrave et al., 2015). Fundamental drivers of potential output growth are further analyzed by applying a growth accounting framework to the estimated potential output growth (see Appendix 2 for details on the methodology).

\section{Even before the pandemic, growth of potential output in Australia and New Zealand}

had slowed (Figure 5). In Australia, low productivity growth and weak capital accumulation of both the mining and non-mining sectors contributed to the slowdown in potential output

Figure 5: Potential Growth Moderated Even Before the Pandemic (Pre-COVID potential growth, percent or percent points)

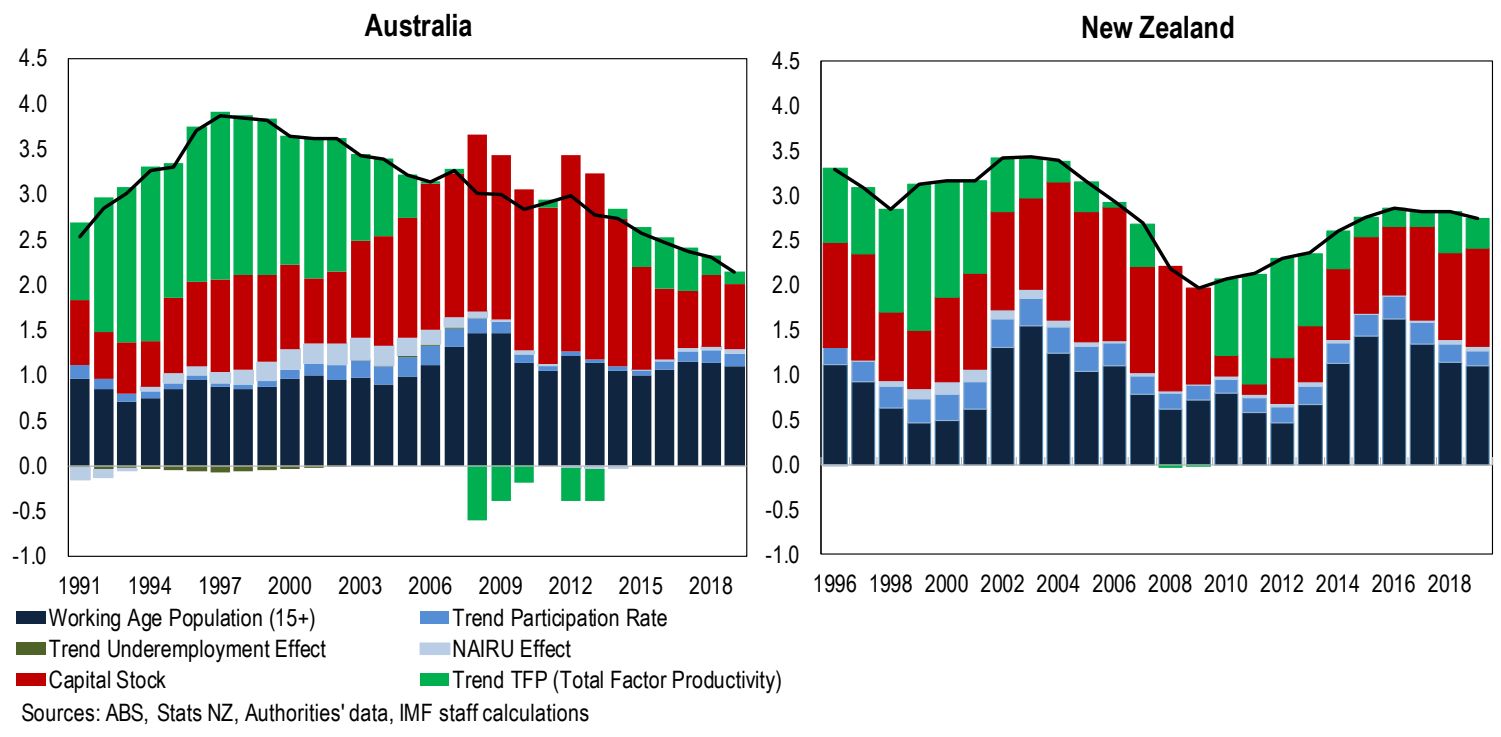

\footnotetext{
${ }^{14}$ As the current crisis is a global recession, the decline in world growth is likely to have a negative effect on individual countries, including Australia and New Zealand. As such, we do not control for aggregate shocks by including year fixed effects in our baseline specification as these shocks are highly relevant in the current crisis. Results are also robust to other changes in specification, such as including leads of the recession dummy as suggested by Teulings and Zubanov (2013).
} 
after the mining boom of the early 2010s. ${ }^{15}$ In New Zealand, recent weak productivity growth was masked by strong working age population growth, which was driven by immigration, along with a rising capital stock.

\section{B. TRANSMISSION CHANNELS OF THE PANDEMIC ON POTENTIAL OUTPUT}

The pandemic is likely to affect the fundamental drivers of potential output. Mediumterm potential output for Australia and New Zealand is analyzed with a simple growth accounting framework, examining the impact of the crisis on total factor productivity, capital, and labor (Appendix 3). The effect on labor supply is further broken down into effects on the non-accelerating inflation rate of unemployment (NAIRU), labor force participation, and working-age population growth given immigration trends. Overall, we find that the current crisis is likely to affect medium-term potential output significantly in Australia and New Zealand through all of these channels. Given the nature of the COVID-19-induced recession, some transmission channels will likely differ significantly from previous recessions.

\section{Non-Accelerating Inflation Rate of Unemployment}

\section{The pandemic and needed containment measures have induced a large sectoral}

reallocation. In Australia and New Zealand, labor market adjustment has been uneven across sectors, and job losses have been concentrated in some service sectors dependent on personal

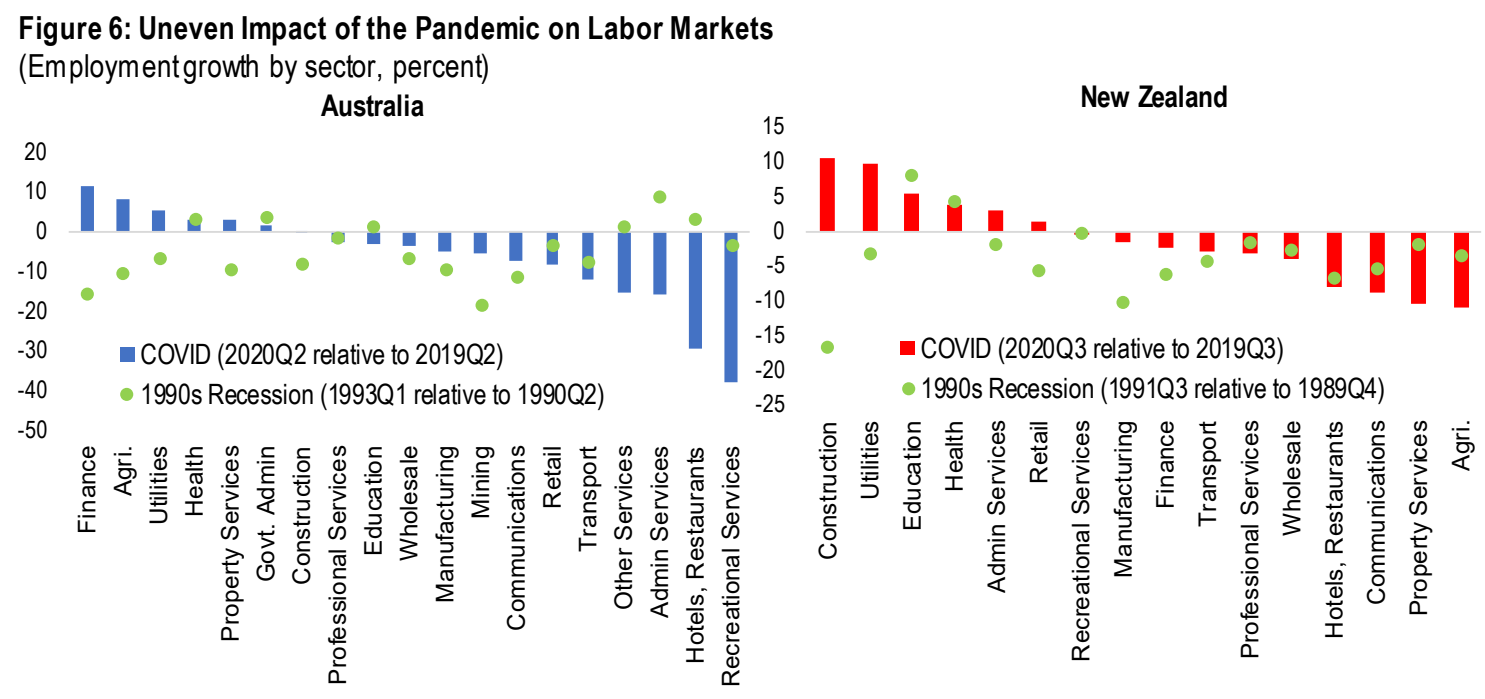

Source: ABS and Stats NZ

\footnotetext{
${ }^{15}$ See Kido et al. (2020), Hambur and Jenner (2019) and Van der Merwe et al. (2018) for determinants of nonmining business investment in Australia.
} 
contact, such as

accommodation, food

services, and recreational

services (Figure 6). ${ }^{16}$

Uneven patterns of

economic impacts across

sectors are also observed in

sectoral stock returns

(Figure 7). The degree of

sectoral reallocation taking

place in Australia and New

Zealand in the current crisis,

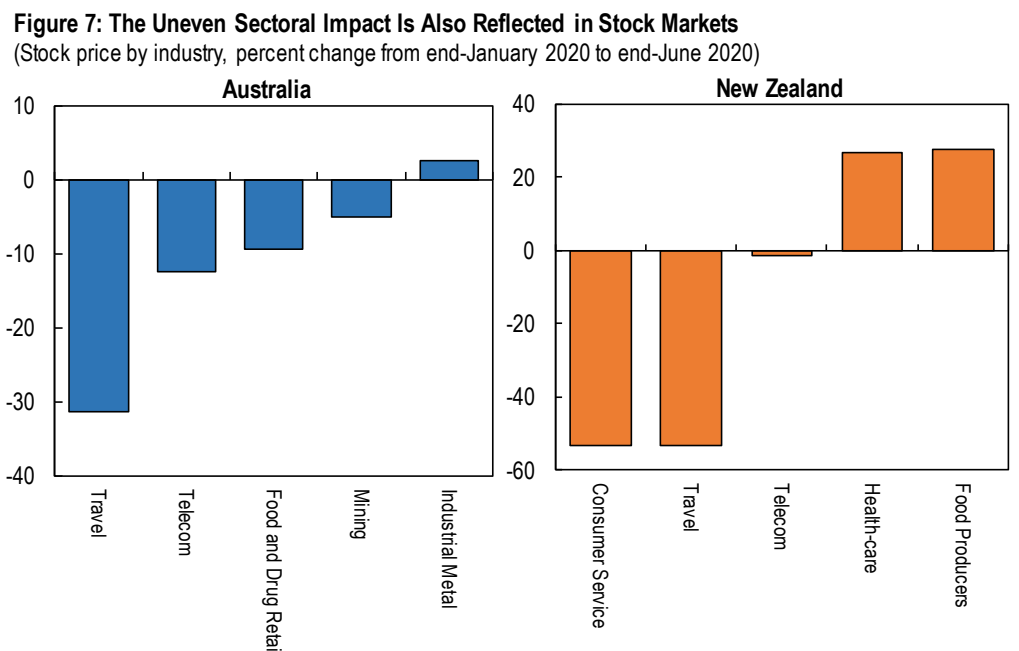

as measured by dispersion across sectors in employment growth and stock returns, is the largest in the last 20 years (Figure 8 and Appendix 4).

The large sectoral reallocation is expected to raise the NAIRU. The heightened degree of sectoral reallocation is expected to increase skills mismatches in the labor market, as workers do not transition easily between sectors given differences in required skills and experiences. This is expected to lead to a persistent increase in the NAIRU. Previous empirical and theoretical studies confirm this link between skills mismatches and the NAIRU (for example, Jackman and Roper, 1987, and King and Morely, 2007). Estimates from a structural vector autoregression model suggest that unemployment rates in Australia and New Zealand, respectively, will likely increase by around 0.6 and 0.8 percentage point in the medium term due to sectoral reallocation, leading to a 0.3 percent and 0.5 percent loss of potential output, respectively (Figure 9

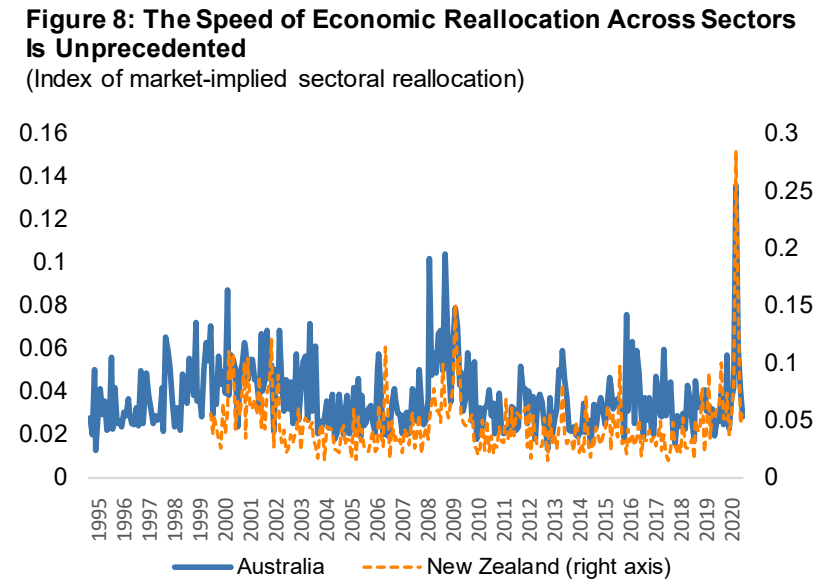

Source: FTSE and IMF staff calculations.

Notes: The figure shows Lilien (1982) sectoral reallocation index caluculated from FTSE industry level stock price data (25 industries for Australia, 12 industries for New Zealand). and Appendix 4).

\footnotetext{
${ }^{16}$ The impact would have been significantly larger without the large-scale policy support both countries have implemented. The observed decline in agricultural sector employment in New Zealand largely reflects a previous, temporary increase in late 2019. For government economic responses to the COVID-19 pandemic, see the IMF Policy Trucker (https://www.imf.org/en/Topics/imf-and-covid19/Policy-Responses-to-COVID-19)
} 


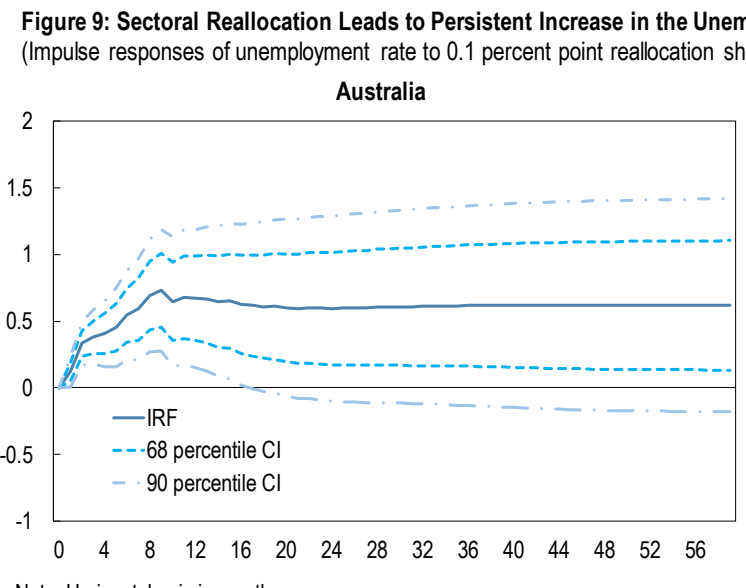

Note: Horizontal axis in months.

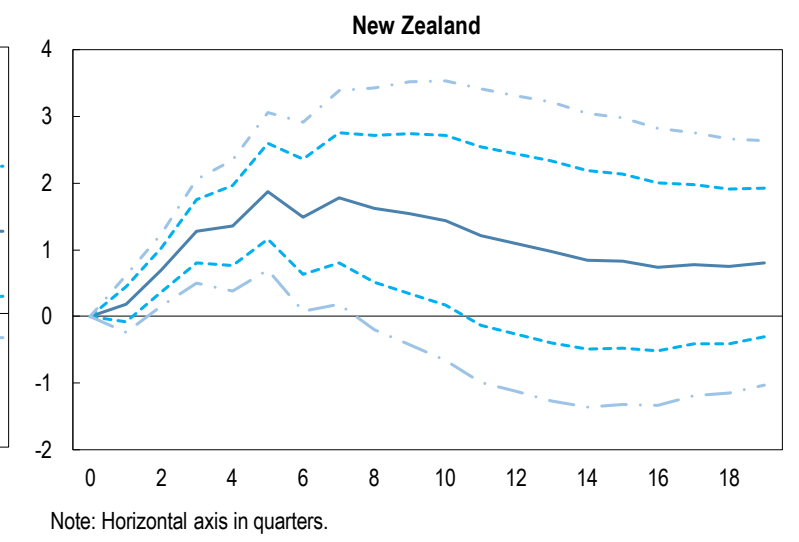

\section{Labor market policies can affect workers' incentives to work, thereby affecting the} unemployment rate beyond the business cycle. In particular, a permanent increase in unemployment benefits is often associated with a higher NAIRU. In New Zealand, social benefits including unemployment benefits have been increased permanently by NZ\$25 per month. Such expansion of unemployment benefits, while clearly warranted in the wake of the pandemic-related lockdowns, is expected to affect labor supply incentives. ${ }^{17}$ OECD crosscountry evidence (Gianella et al., 2008) suggests that the expanded unemployment benefits would be expected to lead to a 0.2 percentage point permanent increase in unemployment in New Zealand, which translates to a 0.1 percent loss of potential output in $2020 .{ }^{18}$

\section{Labor force participation}

Labor force participation is expected to decline moderately in the medium term. Before the pandemic, the labor force participation rate had been on a rising trend in many advanced economies, including Australia and New Zealand. Strong participation had been supported by a secular expansion of service sectors, which provides employment opportunities for

\footnotetext{
${ }^{17}$ We assume that the Coronavirus Supplement in Australia and the COVID-19 Income Relief Payment in New Zealand will not affect NAIRU as they are temporary measures which were implemented at a time of extreme slack in the labor market and are therefore unlikely to have a significant impact on job search incentives.

${ }^{18}$ Gianella et al. (2008) estimate the elasticity of structural unemployment to the unemployment replacement ratio in OECD economies. They find that a 1 percentage point increase in the unemployment replacement ratio leads to 0.03 percentage point increase in the NAIRU. After the pandemic, the net unemployment replacement ratio has been increased by 6 percentage points in New Zealand.
} 
workers (re-)entering the labor market, including female and elderly workers (IMF, 2018). ${ }^{19}$ The strong trend of the labor force participation rate is likely to slow as employment in many service sectors has been severely affected by the pandemic. Labor force statistics in Australia and New Zealand showed an initial, large drop in labor force participation following the lockdowns, particularly among female and young workers. While much of that decline is likely to be temporary, labor force participation rates in Australia and New Zealand could remain below pre-COVID-19 trends by about 0.2 percentage point in the medium term as a result of job losses in the service sectors, though with significant uncertainty given the uncertain outlook for medium-term, post-COVID-19 economic structures. ${ }^{20}$ The lower labor force participation rates would reduce medium-term potential output by 0.1 percent.

\section{Working age population}

Closed borders constrain population growth through immigration. Before the pandemic, the working age population in Australia and New Zealand grew relatively strongly among advanced economies, supported by large net migration, which accounted for 60 percent and 70 percent of population growth in Australia and New Zealand, respectively. With the pandemic, immigration flows have collapsed due to the border closures (Figure 10), and the restrictions are expected to remain in place for a considerable period. Net migration is expected to remain at zero while travel restrictions are in place, and to recover gradually after the restrictions are lifted, recovering to pre-COVID-19 trends in 2024. While the flow of net immigration is expected to recover to pre-COVID-19 trends, the impact of lost net migration in the interim on the stock of immigrants is expected to be permanent, with the medium-term impact on working age population expected to be -2.0 percent and -2.8 percent for Australia and New Zealand, respectively. This translates to a 1.2-1.7 percent loss of potential output in the medium term.

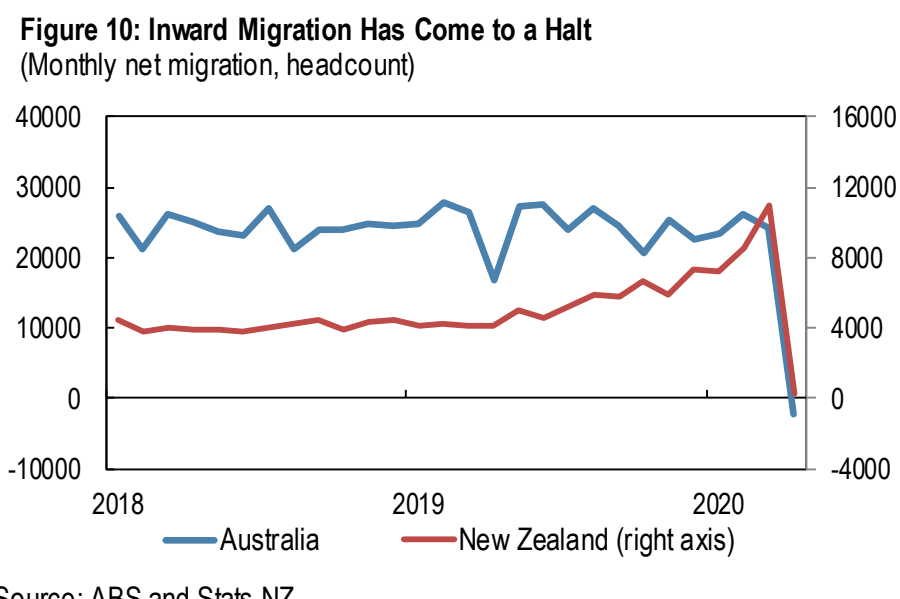

Source: ABS and Stats NZ

\footnotetext{
${ }^{19}$ Using cross country data of 23 advanced economies, IMF (2018) finds that 10 percentage point change in the relative service employment share (the ratio of services to manufacturing employment) leads to 0.1 percent increase in the labor force participation rate.

${ }^{20}$ The impact is calculated from the change in the relative service employment share in the second quarter.
} 


\section{Total Factor Productivity}

\section{As in previous advanced economy recessions, long-lasting effects on TFP can be} expected. In previous recessions, an overall TFP slowdown was driven by a decline in TFP growth within each sector in addition to a reallocation of resources to less-productive sectors, such as from manufacturing to low-productivity services (IMF 2017). ${ }^{21}$ In the current recession in Australia and New Zealand, productivity in each sector is expected to decline as innovative investment, including in research and development, is likely to be impeded by firms' impaired balance sheets and heightened uncertainty. In line with previous advanced economy recessions, TFP is expected to decline due to the within-sector productivity slowdown, which is assumed to reduce TFP and potential output by two percent. ${ }^{22}$

\section{The expected economic reallocation across sectors could offset some of the negative} effects on TFP. In previous recessions in advanced economies, high-productivity sectors, such as manufacturing, were typically disproportionately affected, and low-productivity sectors like services were relatively stable. Such a pattern does not apply to the current crisis, as the sectors most severely affected by the pandemic tend to be lower-productivity service sectors. We estimate the effects of labor reallocation on labor productivity based on the change in sectoral composition of labor and sector-level productivity data (Appendix 3). ${ }^{23}$ As shown in Figure 11, labor reallocation in Australia during the previous recession in the 1990s had adverse effects on productivity, but labor reallocation in the current crisis is estimated to have a positive impact on productivity, reflecting the expected labor shift from lower-productivity to higher-productivity sectors. Such positive impacts of compositional change, estimated at about 0.9 percent,

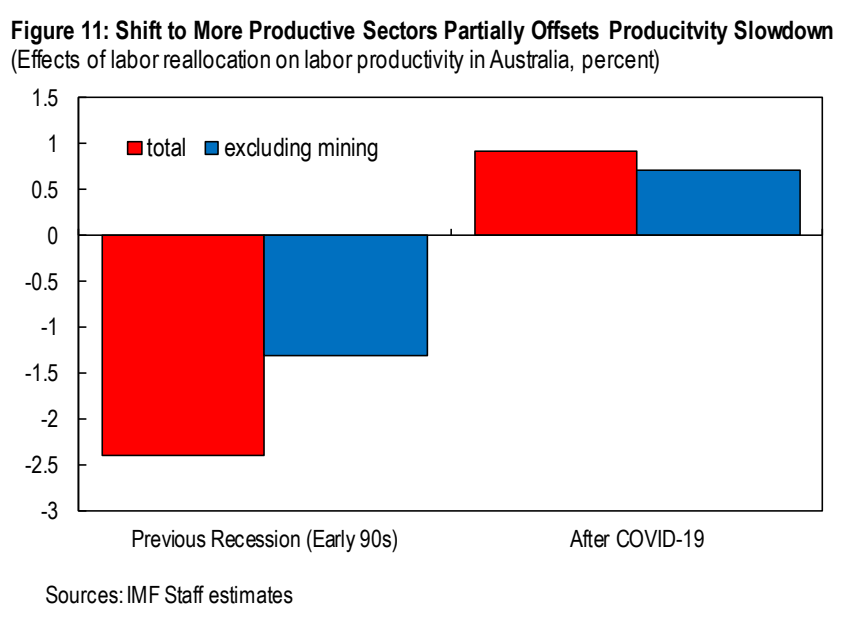

\footnotetext{
${ }^{21}$ It should be noted that labor productivity, an alternative measure of productivity, tended to rise in Australia during previous downturns.

${ }^{22}$ For example, Adler et al. (2017) reports a within sector productivity decline of 2 percent after the global financial crisis.

${ }^{23}$ The other possible channel is reallocation of labor within sectors. Foster et al. (2016) find that reallocation to more productive producers accelerated during the downturn prior to the GFC, but the intensity of reallocation fell rather than rose in the GFC. They also find that the reallocation during the GFC was less productivityenhancing compared to prior recessions.
} 
are expected to partially offset the expected within-sector TFP slowdown and loss of potential output. ${ }^{24}$

\section{Capital accumulation}

\section{As in previous advanced economy recessions, capital accumulation is expected to slow.}

In previous advanced economy recessions, the slowdown of capital accumulation has played a central role in output losses. In the longer run, capital accumulation is expected to follow an endogenous balanced growth path, where capital accumulation is determined by growth in productivity and labor input (for example, Jones, 2005; and Appendix 3). Thus, it is expected that trend capital accumulation will decline due to weak productivity growth and reduced labor supply as a result of muted immigration flows, lower labor force participation, and higher NAIRU. In the medium-term, capital is expected to remain 5 percent and 6 percent below pre-COVID trend in Australia and New Zealand, respectively. Lower capital would reduce medium-term potential output by $2.0-2.4$ percent.

\section{In addition, firms' impaired balance sheets and elevated uncertainty are expected to further weaken capital accumulation. We analyze determinants of investment using} Australia and New Zealand firm-level panel data that include granular firm-level financial information (Appendix 5). ${ }^{25}$ This firm-level exercise sheds lights on drivers of capital accumulation, which may not be captured at an aggregate level.

\footnotetext{
${ }^{24}$ Another possible channel that would affect TFP is reallocation of capital, which we do not analyze explicitly in this paper. The speed of capital reallocation tends to be slower than labor reallocation due to adjustment costs (for example, Eberly and Wang, 2009). In Australia, capital reallocation played a nonnegligible role during the mining investment boom, but otherwise had relatively small impacts on the economy.

${ }^{25}$ Firm level data are obtained from IMF Corporate Vulnerability Unit database, which is based on Worldscope database.
} 


\section{Our empirical results show that firms' investment behavior is determined by firms' financial positions and firm-level uncertainty in addition to expected profitability}

(Figure 12). During the pandemic, many Australian firms have reported significant revenue losses, with disproportionate effects in some service sectors. In an illustrative scenario, where these revenue losses are assumed to result in higher debt levels, firms' capital accumulation could be reduced by about 0.2 percent in 2020 in Australia and New Zealand, and the effects are expected to persist in the medium-term (Figure 13). ${ }^{26}$ Elevated global and domestic uncertainty is also

Figure 12: Debt and Uncertainty Affect Firms' Investment Decisions (Effects of increase in firm's debt-to-asset ratio and stock volatility on inv.-to-capital ratio)
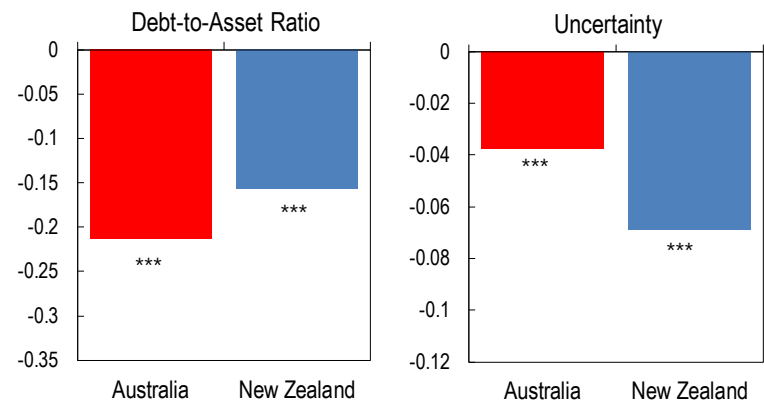

Sources: IMF CVU database and IMF staff estimates Note: Determinants of investment-to-capital ratio are estimated from CVU firm database. *** indicates significance at 1 percent level.

likely to induce firms' wait-and-see

behavior, thereby impeding their investment (Figure 14). Capital accumulation could be reduced further by 0.5 percent in 2020 in Australia and by 0.8 percent in New Zealand, although its effects are likely to be short-lived compared with adverse balance sheet effects. Taken together, deteriorated balance sheets and elevated uncertainty would lead to a 0.3 percent and 0.4 percent loss of potential output in 2020 for Australia and New Zealand, respectively.

Figure 13: Firms' Rising Debt Will Hinder Capital Accumulation (Firm-level impact of rising debt on investment-to-capital ratio for Australian firms, percentage points)

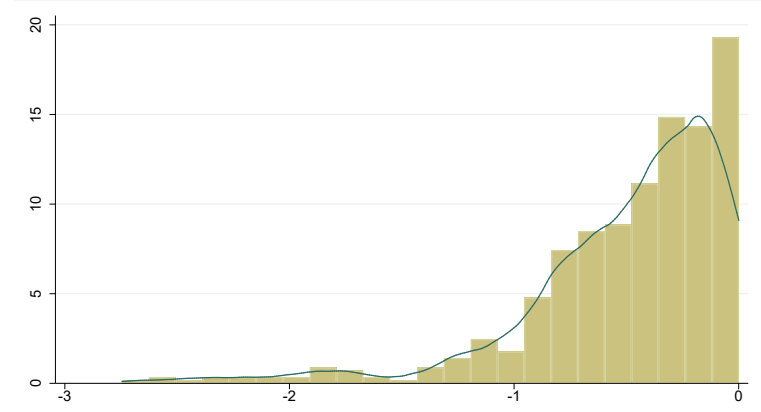

Source: IMF staff calculations.

Notes: vertical axis indicates percent of firms and horizontal axis indicates change in invest-to-capital ratio due to increase in debt-to-asset ratio. Impacts are calucluated based on firm-level investment regression and ABS business survey.
Figure 14: Economic Policy Uncertainty

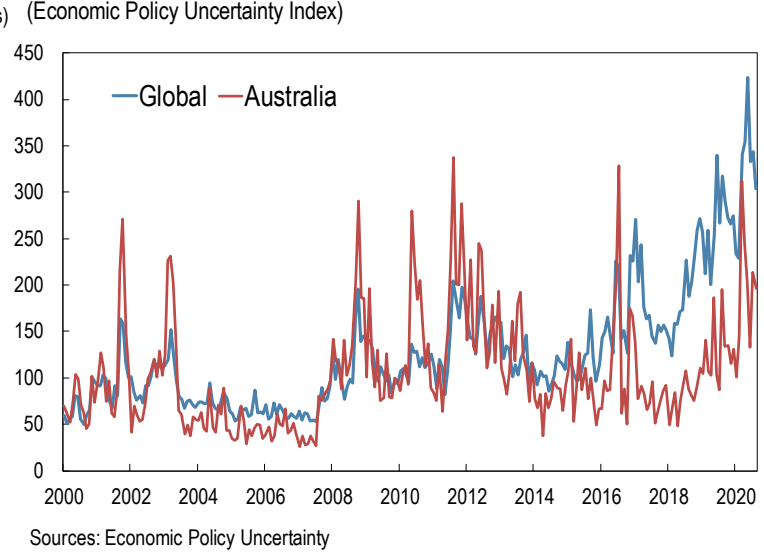

\footnotetext{
${ }^{26}$ This estimation does not incorporate the fiscal support that has been provided to affected firms by the Australian and New Zealand governments. In Australia, the size of government support provided to firms was large enough to offset the initial impact of the pandemic on corporate balance sheets.
} 


\section{PROJECTING MEDIUM-TERM POTENTIAL OUTPUT}

\section{Under the baseline scenario, the fundamental drivers of potential output all point to} subdued medium-term potential output. ${ }^{27}$ The baseline simulation suggests that weaker productivity growth, a slowing pace of capital accumulation and lower labor input all contribute to lower medium-term potential output (Figure 15). Australia's potential output in 2025 is estimated to be 5 percent below the pre-pandemic potential output trend (Figure 16). The expected impact on New Zealand is larger, with potential output in 2025 remaining 6 percent lower than its pre-pandemic trend, reflecting New Zealand's higher reliance on net migration flows. ${ }^{28}$

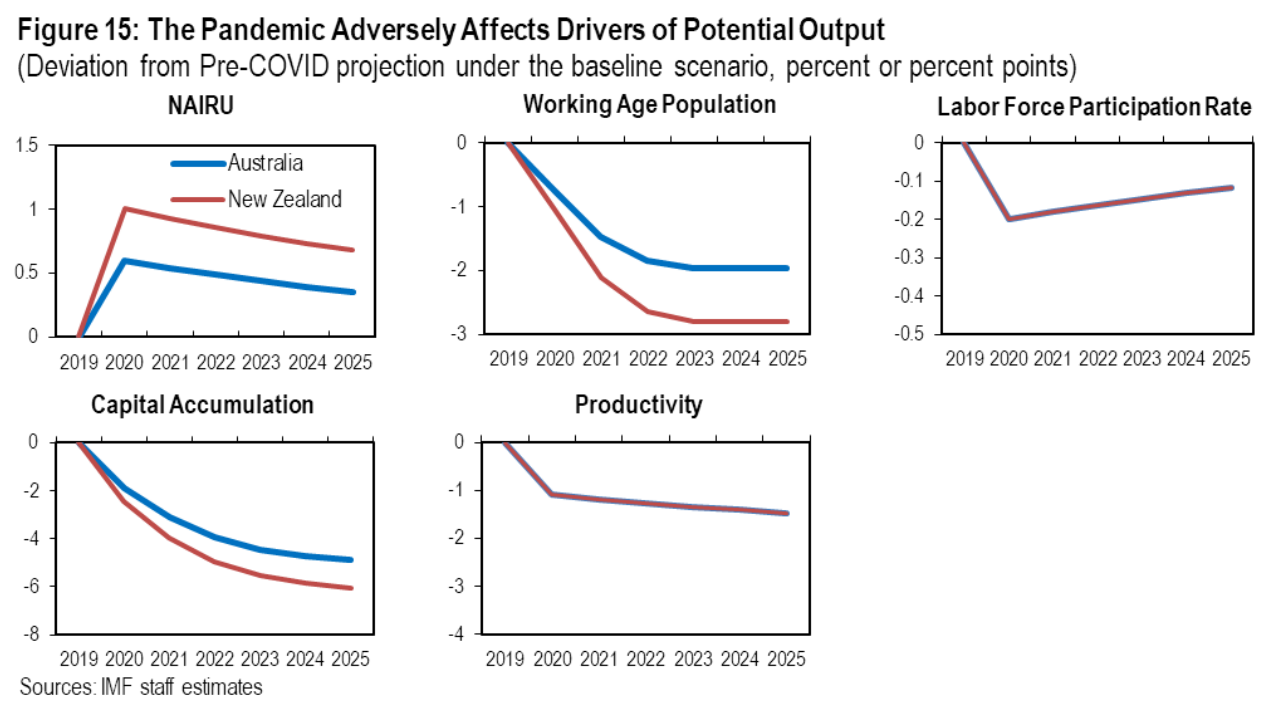

\section{Given high uncertainty around the baseline, multiple alternative scenarios are also}

considered. Downside scenarios include a more sluggish productivity growth scenario and a lower labor force participation rate scenario. Similarly, two upside scenarios are simulated, evaluating the impact of stronger immigration flows and productivity growth.

\footnotetext{
${ }^{27}$ The magnitude of the impact of the pandemic inherently depends on its persistence. Our simulations assume that the authorities will continue to contain health risks successfully and that no major local outbreak will occur in Australia and New Zealand after 2020.

${ }^{28}$ Labor productivity of Australia and New Zealand are both estimated to be $2 \frac{1}{2}$ percent lower than prepandemic trend.
} 
- More sluggish productivity growth. Weaker productivity spillovers from other advanced economies and lost innovation due to muted immigration flows could imply slower productivity growth than in the baseline. Increased market concentration as a result of bankruptcies and weak firm entry could undermine firms' incentive to innovate, further impairing productivity growth. In addition, increased risk aversion among workers may hinder their shift to more productive producers. In this scenario, within-sector productivity in the medium-term will be 3.5 percent lower than preCOVID, which is nearly double the decline assumed in the baseline.

- Lower labor force participation rate. In advanced economies including Australia and New Zealand, many workers have left the labor market in the wake of the pandemic. While the baseline scenario assumes that labor force participation will largely recover, this downside scenario assumes that labor force participation rates will remain 0.8 percent below pre-COVID trends in the medium term, as more workers remain on the sidelines for longer or enter early retirement given reduced opportunities to work and gradually depreciating skills.

- Stronger immigration flow. Under this scenario, immigration flows will be stronger than assumed in the baseline scenario. Travel restrictions are assumed to be lifted earlier, with immigration flows resuming at a faster pace in 2021. From 2022, net migration to Australia and New Zealand would reach levels above the pre-pandemic trend, fully offsetting the decrease during the border closure.

- Stronger TFP growth. The pandemic may induce firms' efforts to adopt new technologies, including information and communication technology (ICT) investment, thereby promoting a shift to a more productive, digitalized economy. Under this scenario, following a 2 percent decline in 2020, within-sector productivity is assumed to grow faster than under the pre-COVID trend in the medium-term, recovering to near preCOVID trend levels in the medium-term $(0.5$ percent below the pre-COVID trend in 2025). 
The alternative scenarios illustrate the robustness of the expectation of permanent potential output losses, albeit with uncertain magnitude (Figure 17). Under the two downside scenarios, potential output for Australia and New Zealand in 2025 will remain well below pre-COVID trends and baseline projections, with potential output for Australia 6-71/4 percent lower than pre-COVID trends, and potential output for New Zealand $71 / 4-81 / 2$ percent below pre-COVID trends. Even under the two upside scenarios, potential output for Australia will remain 23/4-31/4 percent lower than the pre-COVID trend, and potential output for New Zealand will remain 33/4-4 percent below its pre-COVID trend. ${ }^{29}$

Figure 17: COVID-19's Economic Impact Will Be Sustained Also Under Alternative Scenarios (Projected potential output, 2015=100)

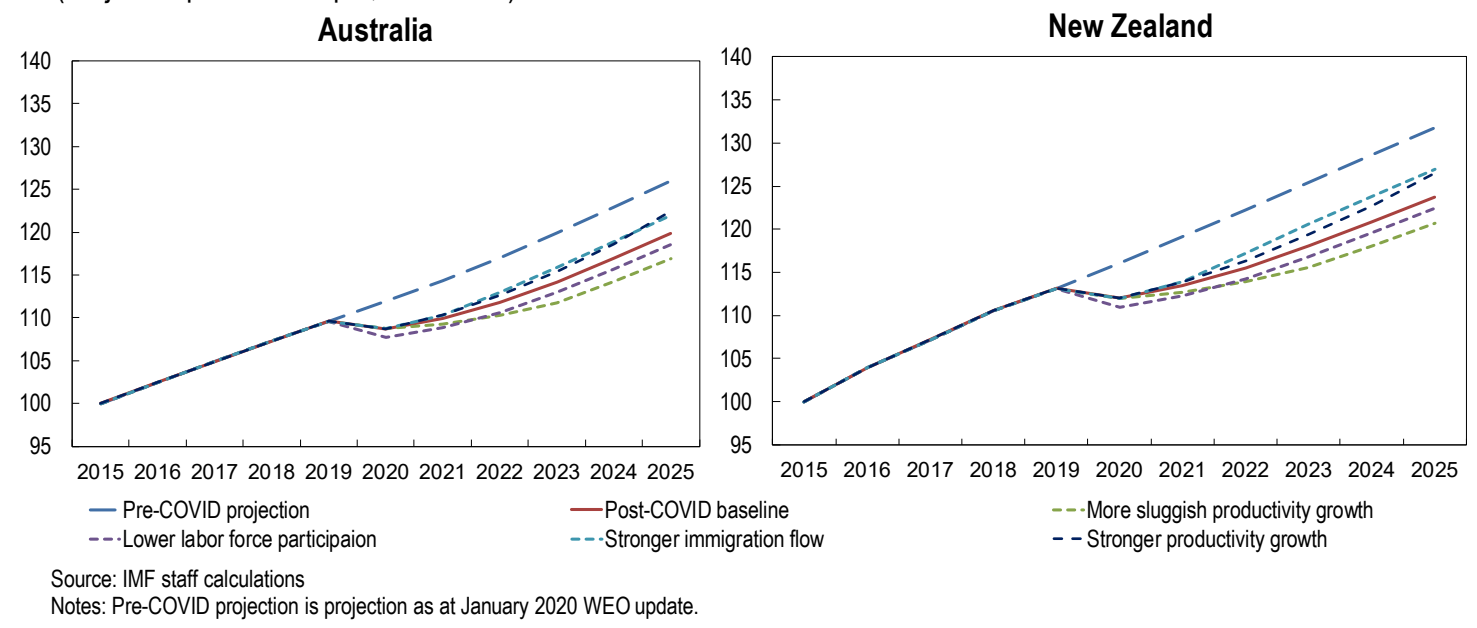

\section{Policy Implications And Conclusions}

\section{The pandemic is likely to have persistent scarring effects on potential output in}

Australia and New Zealand. While the nature of the current crisis is arguably different from previous crisis in advanced economies, several channels point to long-lasting effects on productive capacity in Australia and New Zealand. Medium-term potential output is likely to be reduced by weak productivity growth, slower capital accumulation and lower labor inputs. Sizable output losses are expected even under relatively optimistic scenarios.

Maintaining macroeconomic policy support until the recovery is firmly entrenched and stepping up economic reforms will be paramount to mitigate COVID-19's fallout on medium-term output. In addition to tackling the effects of a deep near-term recession, policymakers should swiftly embrace the challenging task of boosting potential output in the

\footnotetext{
${ }^{29}$ Labor productivity in Australia and New Zealand will remain 1/4-43/4 below pre-COVID trends under alternative scenarios.
} 
medium-term while ensuring that the recovery is inclusive and protects those most impacted by the crisis. ${ }^{30}$ As policy steps taken to address short-term needs can have significant medium-term effects, potentially mitigating or exacerbating scarring, it is essential that policymakers develop a holistic policy strategy that encompasses medium-term goals.

\section{Vigorous fiscal and monetary stimulus should be maintained as long as needed to} support demand and limit the medium-term fallout from scarring. Australia and New Zealand have implemented large-scale fiscal stimulus, featuring wage subsidies, and supportive monetary policy, which together have played a pivotal role in mitigating the shortterm losses of the crisis. A premature withdrawal of stimulus would risk unravelling the incipient recovery, leading to a deeper recession that would aggravate scarring. As such, accommodative monetary policy should be maintained for a significant amount of time. ${ }^{31}$ Furthermore, given the substantial fiscal space in Australia and New Zealand, the fiscal deficit should only be lowered gradually, avoiding steep fiscal cliffs as emergency programs (for example, Australia's JobKeeper program) are wound down. Additional discretionary measures can be especially helpful as fiscal multipliers are likely to be large during the recession and in a low-interest-rate environment (Owyang et al., 2013, and Miyamoto, 2018). ${ }^{32}$

\section{As the recovery gets under way, a shift in focus will be needed to render growth more} robust and inclusive. ${ }^{33}$ In particular, priorities should be to allow adequate reallocation of resources across sectors, support workers and firms that are impacted by the transition, and implement reforms to boost productivity growth and investment. ${ }^{34}$ Policies that can be considered include:

\section{- Labor market policies to encourage reallocation while protecting the vulnerable:}

Wage subsidy programs introduced in Australia and New Zealand have played an instrumental role in maintaining workers' attachment with the labor force during the

\footnotetext{
${ }^{30}$ Similar policy implications were recommended in the aftermath of the GFC for OECD countries (Bouis and Duval, 2011) and for Middle Eastern and Central Asian countries (Mitra et al., 2016).

${ }^{31}$ Demand support would not only help close the output gap but would also support capital deepening and adoption of technologies embodied in new physical capital.

${ }^{32}$ Australia's recent FY2021 Commonwealth budget contains significant additional fiscal measures and constitutes welcome support for the post-COVID recovery.

${ }^{33}$ Our policy discussion assumes no major local outbreak of the virus after 2020 and an onset of economic recovery from 2020Q3. Policies should be reprioritized flexibly if health risks emerge again.

${ }^{34}$ Support for workers and firms will be all the more important as some structural reforms have been found to affect the distribution of income, while still having a positive effect on growth (see for example, Ostry et al., 2018).
} 
acute phase of the crisis. However, as the recovery takes hold and health risks diminish, this exceptional support should be gradually phased out to facilitate people moving to new and more productive jobs. To speed up the transition and encourage firms to hire new workers, well-designed and targeted hiring subsidies can be considered. Active labor market policies, including retraining programs that help workers acquire new skills, can reduce skill mismatch and support reallocation of workers. As the transition for workers can take time, ensuring adequate safety nets is essential to protect those most impacted by the economic dislocation. Adequate unemployment insurance, potentially linked to regional economic conditions in the event of localized lockdowns, can play an important role in this regard. Well-designed tax and expenditure policies would boost labor force participation, particularly for women and older workers (IMF, 2012).

\section{- Scaling up government investment to support the recovery and build productive} capacity: The fiscal resources that are freed up from winding down emergency programs like wage subsidies can be redeployed towards productive investments that will spur medium-term growth. Stepped-up investment in infrastructure can play a central role in this regard. A green investment push could spur capital spending in sectors like construction, while also speeding up the transition to a lower-carbon growth path. More broadly, efforts to promote investment in new growth areas, including digital technologies, can help with the post-pandemic reorganization of the economy, while also boosting medium-term productive capacity. Scaling up research spending can facilitate innovation and technology adoption.

- Structural reforms to boost medium-term growth: Reforms to simplify business processes, improve competition in product and service markets, and reduce the regulatory and tax burden can boost innovation, productivity, and investment (IMF, 2016; OECD, 2010). As these reforms typically take significant time to boost output, the time to start is now to support medium-term growth and living standards. Furthermore, liquidity and other government support, which have been instrumental in keeping firms afloat during the crisis, should be phased out gradually, which would provide incentives for non-viable firms to exit and the necessary economic adjustments to take place. Residual support will be needed going forward to ensure the survival of viable firms, including to finance necessary restructuring. ${ }^{35}$

\footnotetext{
${ }^{35}$ Implementing a policy to support viable firms will be challenging as it is often difficult to distinguish between solvent and insolvent firms, especially in an environment of heightened uncertainty.
} 


\section{Appendix 1: Cross-Country Evidence}

Section III of the working paper provides cross country evidence on the persistent effects of recessions. This appendix provides methodological details.

\section{Methodology}

We use standard local projection models (LPMs) to estimate the medium-term dynamics around recession episodes. LPMs involve estimating impulse responses to shocks by running separate regressions for each time horizon (h) of the form:

$$
Y_{i, t+h}-Y_{i, t-1}=\alpha_{i}^{h}+\beta^{h} R E C_{i, t}+\gamma^{h} X_{i, t}+\varepsilon_{i, t}
$$

where $R E C_{i, t}$ is a dummy variable for the start of a recession taken from Martin et al (2015), $X_{i, t}$ is a vector of control variables including lagged values of the recession dummy and lagged differences of the dependent variable, and $\alpha_{i}^{h}$ are country fixed effects. The dependent variable represents changes over different horizons of our variable of interest, $Y_{i, t}$. For $Y_{i, t}$, we use different variables, including log GDP and its various components: log of TFP, log of the capital stock, log of employment, the unemployment rate, and the labor force participation rate. Separate regressions are estimated for each variable.

The coefficient $\beta^{h}$ directly estimates the impulse response for horizon $\mathrm{h}$ in response to a shock to the recession variable. Standard errors are clustered at the country level.

In our baseline specification we do not include year fixed effects. This is because the current crisis is a synchronized shock impacting all countries, therefore, to get context on how GDP and its components may respond to this crisis, excluding year fixed effects from the crosscountry analysis is appropriate. We report robustness of our main result to including year fixed effects in Figure 4 of the main paper.

\section{Sample}

We focus attention on advanced economies as these are most comparable to Australia and New Zealand. Our exact country and time coverage is dictated by the availability of recession start dates.

In our baseline specification, we use recession start dates for 23 advanced economies as identified by Martin et al. (2015). The exact time coverage differs from country to country but broadly covers the period 1970 to 2012 . 
As a robustness check, we also use recession dates as identified by Dovern and Zuber (2020). This allows us to include a slightly broader country coverage (27 countries), though the time coverage is reduced to the period 1990 to 2017.

\section{Data}

Our specifications use data at the annual frequency. Data on our main dependent variables (GDP and its components) is taken from Penn World Table 9.1 (PWT) and the OECD. In particular, we take data for GDP, TFP, employment and capital stock from PWT. We supplement this with data on unemployment rate and labor force participation rate from the OECD.

In addition, we use data on crisis episodes by Laeven and Valencia (2018). We use this data to identify large recessions that were not accompanied by a banking or currency crisis i.e. recessions which did not have a banking or currency crisis a year before or after the start of the recession. 


\section{APPENDIX 2: ESTIMATION OF POTENTIAL OUTPUT BEFORE THE PANDEMIC}

Section IV of the working paper provides estimates of potential output for Australia and New Zealand before the pandemic. This appendix provides methodological detail.

\section{Methodology}

The estimates of potential output presented in Figure 5 of Section IV are computed using a semi-structural multivariate filter model that incorporates a Phillips curve and Okun's law. ${ }^{1}$ The structure of the model can be summarized as follows. The output gap $y_{t}$ is defined as the deviation of observable $\log$ real output $Y_{t}$ from $\log$ potential output $Y_{t}^{*}$.

$$
y_{t}=Y_{t}-Y_{t}^{*}
$$

The dynamics of output can be defined by following three equations.

$$
\begin{gathered}
Y_{t}^{*}=Y_{t-1}^{*}+G_{t}+\varepsilon_{t}^{Y^{*}} \\
G_{t}=\theta G^{s s}+(1-\theta) G_{t-1}+\varepsilon_{t}^{G} \\
y_{t}=\Phi y_{t-1}+\varepsilon_{t}^{y} \quad(A 2 .
\end{gathered}
$$

The level of potential output evolves according to potential growth $G_{t}$ and shock term $\varepsilon_{t}^{Y^{*}}$, which can be interpreted as supply-side shocks. Potential growth is subjected to shock $\varepsilon_{t}^{G}$, and converges to steady-state growth rate. Output gap follows AR (1) process and is also subject to shock $\varepsilon_{t}^{y}$, which is interpreted as demand shocks.

The model also incorporates a (hybrid) Phillips curve, which links output gap to observable inflation.

$$
\pi_{t}=\lambda \pi_{t+1}+(1-\lambda) \pi_{t-1}+\beta y_{t}+\varepsilon_{t}^{\pi}
$$

where $\pi_{t}$ denotes inflation.

In addition, the model employs the observed unemployment rate to help identify unobservable variables. Okun's law links the output gap to the unemployment rate gap $u_{t}$, the deviation of unemployment rate $U_{t}$ from the nonaccelerating inflation rate of unemployment rate (NAIRU) $U_{t}^{*}$.

$$
\begin{gathered}
u_{t}=\gamma u_{t-1}+\delta y_{t}+\varepsilon_{t}^{u} \\
u_{t}=U_{t}^{*}-U_{t}
\end{gathered}
$$

\footnotetext{
${ }^{1}$ Discussion in this appendix is based on IMF (2015) and Blagrave et al. (2015). See Blagrave et al. (2015) for further details about the model.
} 
Equation A2.6 is an Okun's law relationship. In Equation A2.7, NAIRU $U_{t}^{*}$ is time-varying and follows:

$$
\begin{array}{r}
U_{t}^{*}=\kappa U^{S S}+(1-\kappa) U_{t-1}^{*}+\mu_{t}+\varepsilon_{t}^{U^{*}} \\
\mu_{t}=\eta \mu_{t-1}+\varepsilon_{t}^{\mu} \quad(A 2.9)
\end{array}
$$

where $U^{S S}$ denotes steady state unemployment rate, and $\mu_{t}$ denotes trend in NAIRU, which is subject to shock $\varepsilon_{t}^{\mu}$.

The estimation uses three observable variables: real GDP, inflation, and the unemployment rate. Annual data (1990-2019 for Australia, and 1995-2019 for New Zealand) are used for estimation, and parameters are estimated with Bayesian estimation techniques. ${ }^{2}$

Estimated potential growth can be decomposed into underlying drivers, namely, capital, NAIRU, trend labor force participation rate, working age population, and total factor productivity, based on Cobb Douglas production function in Equation A5.1 in Appendix 5. ${ }^{3}$ Figure 5 reports estimated potential growth rates before the pandemic for Australia and New Zealand and their decompositions.

\footnotetext{
${ }^{2}$ Priors used in the estimations are reported in Blagrave et al. (2015).

${ }^{3}$ Trend labor force participation rate is obtained by the Hodrick-Prescott filter with smoothing parameter $\lambda=100$.
} 


\section{Appendix 3: Projecting Medium-Term Growth}

Section IV of the working paper analyzes medium-term potential output for Australia and New Zealand. This appendix provides methodological details.

\section{Growth Accounting Framework and Medium-term Projection}

The paper employs growth accounting framework to analyze potential output in the medium term. The framework is based on the standard Cobb-Douglas production function augmented with detailed labor input items.

$$
\ln \left(Y_{t}^{*}\right)=\ln \left(z_{t}^{*}\right)+\alpha \ln \left(K_{t}\right)+(1-\alpha) \ln \left(W A P_{t} \times L P_{t}^{*} \times\left(1-U_{t}^{*}\right)\right)
$$

where $Y_{t}^{*}$ denotes potential output, $z_{t}^{*}$ denotes cyclicality adjusted TFP, $\alpha$ is the constant capital share of the economy (set as 0.4 both for Australia and New Zealand), $K_{t}$ denotes capital level, $W A P_{t}$ denotes working age population, $L P_{t}^{*}$ denotes cyclicality adjusted labor force participation rate and $U_{t}^{*}$ denotes Non-Accelerating Inflation Rate of Unemployment (NAIRU).

The medium-term projection is conducted in terms of the deviation from pre-COVID potential output projections, using potential output projections from the January 2020 World Economic Outlook data vintage as benchmark. First, the trajectory of each right-hand-side variable in the production function in Equation A3.1 is analyzed in terms of its deviation from pre-COVID projections. These deviations are then aggregated into a predicted revision of potential output from pre-COVID trends based on the Cobb-Douglas production function in Equation A3.1. ${ }^{1}$

Figure 15 and 16 of Section IV show each component of potential output and potential output in deviation from pre-COVID projection. Figure 17 shows potential output under different scenarios in level.

\footnotetext{
${ }^{1}$ Shocks on each variable are assumed to decay over the forecast horizon. In each year, sectoral reallocations are assumed to decay by 10 percent, debt overhang effects are assumed to decay by 20 percent, and uncertainty effects are assumed to decay by 50 percent.
} 


\section{Capital Accumulation}

In the simulations above, capital accumulation is $K_{t}$ is endogenously determined in line with growth theory. In the long-run, capital accumulation is assumed to follow a balanced growth path, where capital and output grow at same rate. Balanced growth path of capital is given as

$$
\Delta \ln \left(\mathrm{K}_{\mathrm{t}}^{B G P}\right)=\frac{\Delta \ln \left(z_{t}^{*}\right)}{1-\alpha}+\Delta \ln \left(\mathrm{L}_{\mathrm{t}}^{*}\right)=\frac{\Delta \ln \left(z_{t}^{*}\right)}{1-\alpha}+\Delta \ln \left(W A P_{t} \times L P_{t}^{*} \times\left(1-U_{t}^{*}\right)\right)
$$

where $K_{t}^{B G P}$ denotes the capital level at balanced growth path, and $L_{t}^{*}$ denotes cyclicality adjusted labor input, and $\alpha$ denotes the constant capital share of the economy.

In the simulation, it is assumed that capital accumulation converges gradually to this balanced growth path. ${ }^{2}$ In addition, debt overhang effects and uncertainty effects discussed in Appendix 5 also affect the trajectory of capital accumulation.

$$
\ln \left(K_{t}\right)=(1-\gamma) \ln \left(\mathrm{K}_{\mathrm{t}}^{B G P}\right)+\gamma \ln \left(K_{t-1}\right)+D O_{t}+U_{t}
$$

where $\gamma$ denotes persistence parameter (set at 0.66 both for Australia and New Zealand), $D O_{t}$ denotes debt overhang effects and $U_{t}$ denotes uncertainty effects, both discussed in Appendix 5.

\section{Effects of labor reallocation on productivity}

As discussed in Section IV, the pandemic has induced large sectoral reallocation. The simulations in this paper incorporate such effects of labor reallocation across sectors on productivity following Duarte and Restuccia (2010) and Goodridge et al. (2018). Following Goodridge et al. (2018), output growth can be decomposed into within-sector labor productivity growth, labor reallocation effects and aggregate labor inputs,

$$
\Delta \ln \left(Y_{t}^{*}\right)=\Delta \ln \left(\operatorname{LProd}_{t}^{*, \text { within }}\right)+\mathrm{R}_{\mathrm{t}}^{L}+\Delta \ln \left(W A P_{t} \times L P_{t}^{*} \times\left(1-U_{t}^{*}\right)\right)
$$

where $\operatorname{LProd}_{t}^{* \text {,within }}$ denotes labor productivity growth within sectors, and $\mathrm{R}_{\mathrm{t}}^{L}$ denotes labor reallocation effects on labor productivity. $\mathrm{R}_{\mathrm{t}}^{L}$ captures effects of change in labor composition across sectors, which can be given as follows,

$$
\mathrm{R}_{\mathrm{t}}^{L}=\sum_{i=1}^{n} \frac{\operatorname{Lprod}_{i, t-1}}{\operatorname{Lprod}_{t-1}} \times\left(\frac{L_{i, t}}{L_{t}}-\frac{L_{i, t-1}}{L_{t-1}}\right)
$$

\footnotetext{
${ }^{2}$ Capital is assumed to adjust gradually due to adjustment costs. It is also implicitly assumed that capital level before the pandemic was on balance growth path.
} 
where $\operatorname{Lprod}_{t-1}$ denotes aggregate labor productivity, $\operatorname{Lprod}_{i, t-1}$ denotes sector $i$ 's labor productivity, $L_{\mathrm{i}, \mathrm{t}}$ denotes employment in sector $i$ and $L_{\mathrm{t}}$ denotes aggregate employment. Reallocation effects are obtained with the change in employment share in sectors, multiplied by sector-level labor productivity in the previous period. It takes positive value if there is labor shift from a low-productivity sector to a high-productivity sector.

Figure 11 in Section III shows labor reallocation effects in Australia during the recession in 1990s and COVID-19 episode. ${ }^{3}$ In aggregate growth accounting in Equation A3.1, reallocation effects are included in total factor productivity. ${ }^{4}$

\footnotetext{
${ }^{3}$ Reallocation effects in the 90s' calculated based on labor reallocation from 1990Q3 to 1993Q2, and reallocation effects after COVID-19 is calculated based on labor reallocation from March 14, 2020 to July 25, 2020 (weekly payroll data).

${ }^{4}$ Jorgenson et al. (2007) show labor reallocation effects and capital reallocation effects (not considered in this paper) are included in change in aggregate total factor productivity. For New Zealand, labor reallocation effects in Australia is used, as the labor adjustment after the pandemic is masked by a large-scale wage subsidy program.
} 


\section{APPENDIX 4: SECTORAL REALLOCATION AND ITS EFFECT ON UNEMPLOYMENT RATE}

Section IV of the working paper analyzes sectoral reallocation and the effects of shocks to sector allocation on the unemployment rate. This appendix provides methodological details.

\section{Sectoral Reallocation Index}

The degree of sectoral reallocation is analyzed using the method developed by Lilien (1982). ${ }^{1}$ Sectoral reallocation index is defined as the weighted standard deviation of sectoral differences, computed separately for the stock markets and labor markets:

$$
\sigma_{t}=\left[\sum_{i=1}^{n} S_{i}\left(\Delta \ln x_{i, t}-\Delta \ln X_{t}\right)^{2}\right]^{\frac{1}{2}}
$$

- $\quad$ For the stock market specification, $S_{i}$ denotes the market capitalization share of sector $i, x_{i, t}$ denotes sectoral stock return at time $t$, and $X_{t}$ denotes the total stock market return at time $t$. The index computes weighted standard deviation of sectoral stock returns, therefore quantifies sectoral dispersion at time $t$. Sectoral stock prices are obtained from Financial Times Stock Exchange (FTSE) database. Data for 25 and 12 industries are used for Australia and New Zealand, respectively. The sectoral reallocation index is calculated at monthly frequency. Figure 8 in Section III and the left panel of Figure A4.1 display the estimated sectoral reallocation index for Australia and New Zealand.

- $\quad$ For the labor market specification, $S_{i}$ denotes share of employment in sector $i$, and $x_{i, t}$ denotes sectoral employment at time $t$, and $X_{t}$ denotes the total employment at time $t$. Data for 19 and 16 industries are used for Australia and New Zealand, respectively. The index is calculated at quarterly frequency.

Figure A4.1 shows sectoral reallocation indices estimated separately from stock markets and labor markets. For Australia, large sectoral reallocation is observed both in the stock market and the labor markets. For New Zealand, labor market-implied sectoral reallocation remains low in the second quarter, despite a sharp increase in the stock-implied sectoral reallocation

\footnotetext{
${ }^{1}$ Lilien (1982) analyzes sectoral reallocation in labor market. Brainard and Cutler (1993) apply its methodologies to stock market.
} 
index, as reallocation in labor market is masked by a large-scale wage subsidy scheme provided by the government.

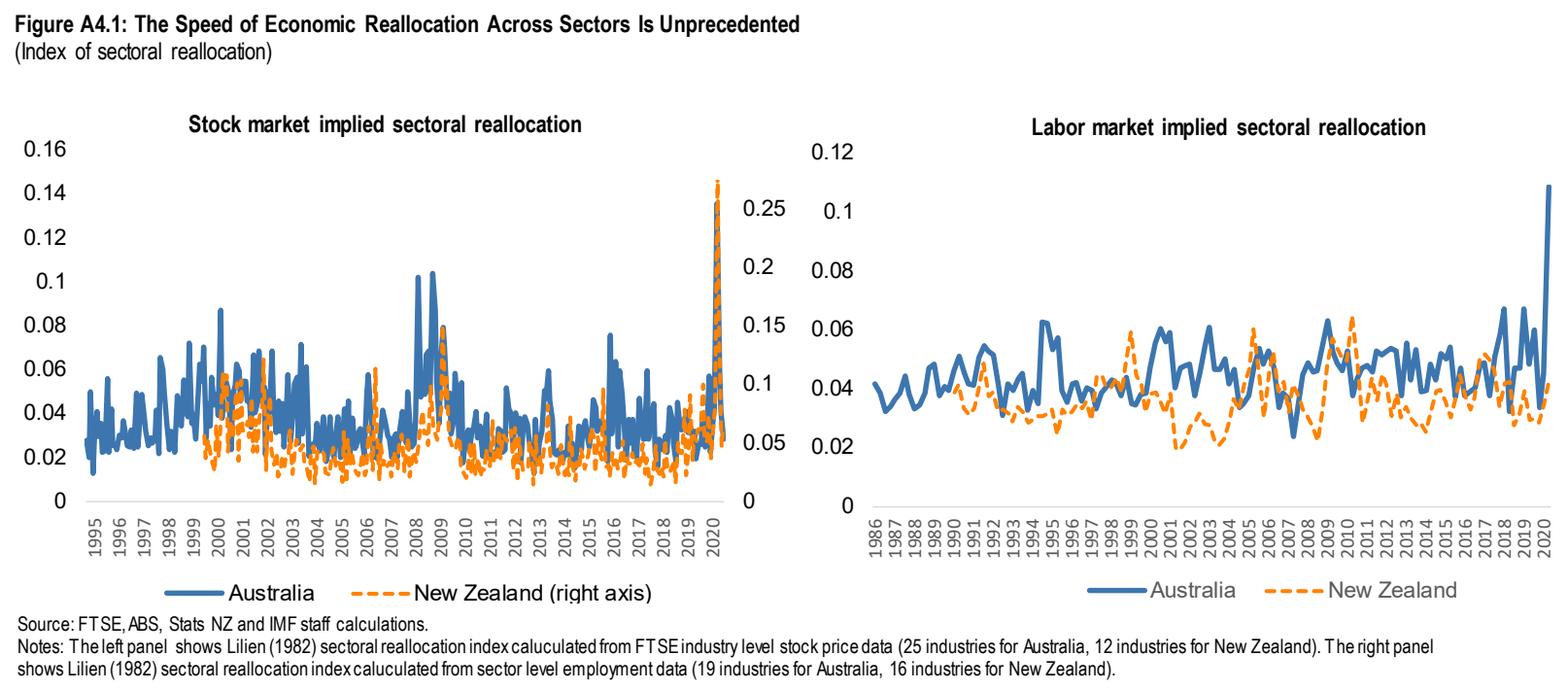

\section{Effects of Reallocative Shocks}

A simple structural vector autoregression model is employed to analyze the effects of reallocation shocks on the unemployment rate. The model is given as:

$$
y_{t}=\beta_{0}+\sum_{k=1}^{m} \beta_{k} y_{t-k}+u_{t}
$$

Where vector $y_{t}$ includes the change in the unemployment rate and the sectoral reallocation index based on stock market returns obtained from Equation A4.1, $\beta_{k}$ is the coefficient matrix on $k$ th lag of $y$, and vectors $\beta_{0}$ and $u_{t}$ represent the constant terms and reduced-form error terms. The equation is estimated at monthly frequency for Australia using data over September 1995-May 2020, and at a quarterly frequency for New Zealand using data over 2000Q4-2020Q1, where unemployment rate is only available at quarterly frequencies. Number of lags are set at 12 for Australia, and 6 for New Zealand.

Following the literature (e.g. Campbell and Kuttner 1996, Tase 2019), sectoral reallocation shocks are identified, using Cholesky decomposition, such that they do not affect the unemployment rate contemporaneously. Figure 9 of Section IV reports cumulative impulse responses of unemployment rate changes to identified reallocation shocks scaled to the magnitude in COVID-19 episode. ${ }^{2}$

\footnotetext{
${ }^{2}$ Results are broadly unchanged if the change in terms of trade is included in the vector autoregression.
} 


\section{APPENDIX 5: EFFECTS OF DEBT OVERHANG AND UNCERTAINTY ON INVESTMENT}

Section IV of the working paper analyzes effects of debt and uncertainty on firm-level investment behavior. This appendix provides methodological details.

\section{Determinants of firm-level investment behavior}

The following panel regression model, a Tobin's Q model augmented with firm-level financial variables and uncertainty, is employed to analyze effects of debt and uncertainty on firms' investment:

$$
\frac{I_{i, t}}{K_{i, t-1}}=\alpha+\tau_{i}+\delta_{t}+\beta X_{i, t}+\varepsilon_{i, t}
$$

where $I_{i, t}$ denotes firm $i$ 's capital expenditure at time $t, K_{i, t-1}$ denotes firm $i$ 's capital stock, and $X_{i, t}$ includes a set of firm-level variables. $X_{i, t}$ includes the debt level (debt-to-asset ratio), firm-level uncertainty (measured as firm-level stock volatility), the cost of debt (interest rate expenditure-to-debt), liquidity (current-asset-to-current-liability ratio), and Tobin's Q (measured as the sum of market value of equity and book value debt divided by book value of asset). ${ }^{1}$ The regression includes firm-level and time fixed effects, and firm-clustered robust standard errors are estimated. All explanatory variables are included with a one-year lag to preempt endogeneity issues. Firm-level data are of annual frequency, obtained from the IMF Corporate Vulnerability

Unit Database, which is based on the Worldscope database. Firms in the financial sector are excluded Table A5.1 Determinants of firm-level investment from the sample and firm-

\begin{tabular}{|c|c|c|}
\hline $\begin{array}{l}\text { Dependent Variable: } \\
\text { Investment-to-Lagged Capital }\end{array}$ & Australia & New Zealand \\
\hline \multirow[t]{2}{*}{ Cost of Debt (-1) } & $-0.404^{* * *}$ & -0.124 \\
\hline & $(0.097)$ & $(0.171)$ \\
\hline \multirow{2}{*}{ Debt (-1) } & $-0.213^{\star \star \star}$ & $-0.157^{\star \star \star}$ \\
\hline & $(0.027)$ & $(0.046)$ \\
\hline \multirow[t]{2}{*}{ Liquidity (-1) } & $0.009^{\star * *}$ & $0.013^{*}$ \\
\hline & $(0.002)$ & $(0.007)$ \\
\hline \multirow[t]{2}{*}{ Uncertainty $(-1)$} & $-0.037^{\star * *}$ & $-0.069^{\star * *}$ \\
\hline & $(0.012)$ & $(0.034)$ \\
\hline \multirow[t]{2}{*}{ Tobin's Q (-1) } & $0.019^{\star \star *}$ & $0.044^{\star \star *}$ \\
\hline & $(0.005)$ & $(0.007)$ \\
\hline R-squared & 0.064 & 0.058 \\
\hline Sample Period & $1994-2018$ & $1990-2019$ \\
\hline Number of Observation & 7,893 & 1,443 \\
\hline
\end{tabular}

Note: In the table, ${ }^{* \star *}$ and ${ }^{*}$ indicate statistical significance at 1 and 10 percent level, respectively. Time fixed effects and firm fixed effects are controled.

reported in Figure 12 of Section IV. Table A5.1

reports the comprehensive regression results.

\footnotetext{
${ }^{1}$ Although theoretically Tobin's Q is a sufficient statistic for investment under certain assumptions, other variables have commonly been found to have important additional explanatory power (Bond and Reenen, 2007).
} 


\section{Effects of debt overhang}

To analyze the effects of rising debt due to COVID-19, first, the increase in debt is estimated using business survey data. Business survey data compiled by the Australian Bureau of Statistics provide information on revenue losses due to COVID-19 at the sectoral level (Figure A5.1). ${ }^{2}$ Based on firm-level data used for the above panel regression and sectoral information on revenue losses, the increase in debt level is projected using the following equation:

$$
\begin{gathered}
\Delta D_{i, t}=\delta *(1-T) * \frac{1}{4} *\left\{S_{i, t}^{-75 \%} *(-.75) * \mathrm{R}_{i, t-1}+S_{i, t}^{-50 \%} *(-.625) * \mathrm{R}_{i, t-1}+S_{i, t}^{-25 \%} *\right. \\
\left.(-.375) * \mathrm{R}_{i, t-1}+S_{i, t}^{-L 25 \%} *(-.125) * \mathrm{R}_{i, t-1}\right\}
\end{gathered}
$$

where $\Delta D_{i, t}$ denotes change in debt, $T$ denotes effective corporate tax (which is set at 0.3 in the simulation), $R_{i, t-1}$ denotes revenue in previous period, and $S_{i, t}^{j}$ denotes share of firms in the sector that report revenue loss at range $j$, $\delta$ denotes elasticity of debt to revenue loss (set as 0.8 , based on cross-country analysis by De Vito and Gomez, 2020). ${ }^{3}$
Figure A5.1. Impact of COVID-19: Revenue Loss of Australian Firms (percent of firms, revenue loss compared to previous year)

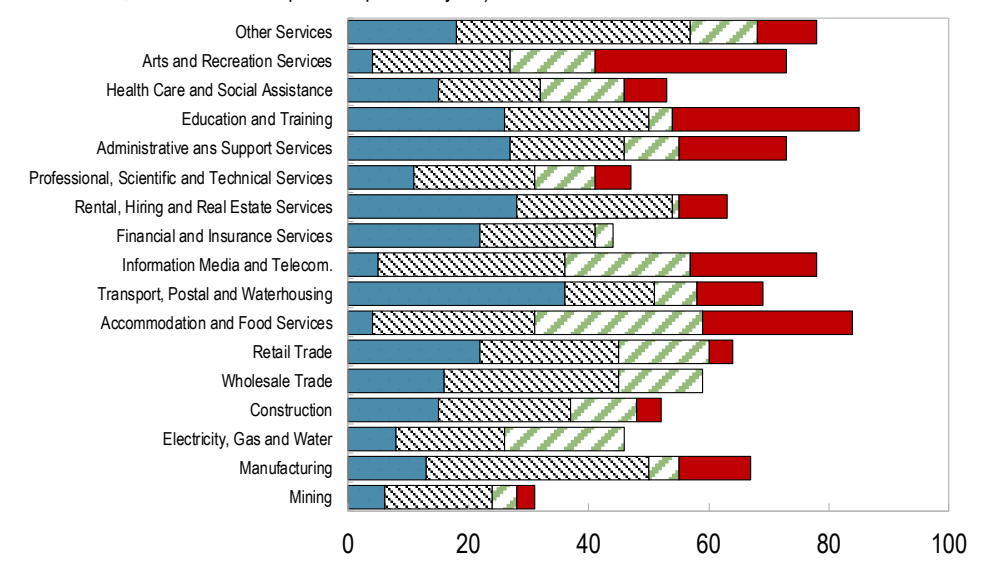

$\square$ Up to 25 percent lower $\square 25-50$ percent lower $\square 50-75$ percent lower $\square$ Greater than 75 percent lower Source: ABS

Based on the projected firm-level increase in debt and sensitivity parameters obtained in Equation A5.1, firm-level debt overhang effects can be estimated as:

$$
\Delta(I / K)_{i, t}=\beta_{\text {debt }} \frac{\Delta D_{i, t}}{A_{i, t-1}}
$$

where $\Delta(I / K)_{i, t}$ denotes the impact of debt on firm $i$ 's investment (expressed as the change in its investment-to-capital ratio), $\beta_{\text {debt }}$ denotes the regression coefficient on the debt level (debt-to-asset ratio) from Equation A5.1, and $A_{i, t-1}$ denotes firm $i$ 's total asset at previous period ( $\frac{\Delta D_{i, t}}{A_{i, t-1}}$ is estimated change in debt-to-asset ratio). Figure 13 of section III displays the

\footnotetext{
${ }^{2}$ Business Impacts of COVID-19, June 2020 (5676.0.55.003).

${ }^{3}$ The survey measures revenue losses at five ranges, namely 0-25 percent, 25-50 percent, 50-75 percent, and greater than 75 percent. In Equation A5.2, $S_{i, t}^{j}$ is determined based on the sector the firm $i$ belongs.
} 
distribution of firm-level debt overhang effects for Australian firms. The aggregate level of debt impact on capital accumulation is obtained using a weighted average of firm-level impacts. ${ }^{4}$

\section{Effects of uncertainty}

Similarly, firm-level impacts of increased uncertainty can be obtained based on parameters obtained in the panel regression in Equation A5.1. The impact of uncertainty is given as:

$$
\Delta(I / K)_{i, t}=\beta_{\sigma} \Delta \sigma_{t}
$$

where $\Delta(I / K)_{i, t}$ denotes the uncertainty effect on firm $i$ 's investment (expressed as the change in the investment-to-capital ratio), $\beta_{\sigma}$ denotes the regression coefficient on uncertainty (firm-level stock volatility), and $\Delta \sigma_{t}$ denotes the change in uncertainty. Due to data limitations, we calculate the aggregate level change in uncertainty based on S\&P/ASX200 VIX index and apply that to firm-level uncertainty. ${ }^{5}$ Therefore, aggregate level effects are also obtained by Equation A5.4.

\footnotetext{
${ }^{4}$ For New Zealand, we assume aggregate debt effects similar to Australia due to data availability issues. In doing so, difference in parameters reported in Table A5.1 is adjusted.

${ }^{5}$ Due to limited data availability, change in S\&P/ASX200 VIX is also applied to New Zealand data.
} 


\section{References}

Abiad, A., R.Balakrishnan, P. Koeva Brooks, D. Leigh, and I. Tytell, 2009, "What's the Damage? Medium-term Output Dynamics after the Banking Crises," IMF Working Paper $\mathrm{WP} / 09 / 245$.

Adler, G., R. Duval, D. Furceri, S. Celik, K. Koloskova, and M. Poplawski-Ribeiro, 2017, "Gone with the Headwinds: Global Productivity," IMF Staff Discussion Note $\mathrm{SDN} / 17 / 04$.

Alichi, A., O. Bizimana, S. Domit, E. Fernandez Corugedo, D. Laxton, K. Tanyeri, H. Wang, and F. Zhang, 2015, "Multivariate Filter Estimation of Potential Output for the Euro Area and the United States," IMF Working Paper WP/15/253.

Alichi, A., H. Avetisyan, D. Laxton, S. Mikhatrishvili, A. Nurbekyan, L. Torosyan, and H. Wang, 2019, "Multivariate Filter Estimation of Potential Output for the United States: An Extension with Labor Market Hysteresis," IMF Working Paper, WP/19/35.

Angelini, E., M. Damjanovic, M. Darracq Paries and S. Zimic, 2020, "ECB-BASIR: a primer on the macroeconomic implications of the COVID-19 pandemic," European Central Bank, Working Paper No. 2431, June 2020.

Arsov, I. and B. Watson, 2019, "Potential Growth in Advanced Economies," Research Bulletin, Reserve Bank of Australia, December 2019.

Ball, L., 2014, "Long-Term Damage from the Great Recession in OECD Countries," European Journal of Economics and Economic Policies: Intervention, Vol. 11, No. 2, pp. 149-160.

Barrero, J. N. Bloom, and S. Davis, 2020, “COVID-19 Is Also a Reallocation Shock,” NBER Working Paper 27137.

Bekaert, G., E. Engstrom, and A. Ermolov, 2020, "Aggregate Demand and Aggregate Supply Effects of COVID-19: A Real-Time Analysis," Finance and Economics Discussion Series 2020-049. Washington: Board of Governors of the Federal Reserve System, https://doi.org/10.17016/FEDS.2020.049.

Benati, L., 2012, “Estimating the Financial Crisis' Impact on Potential Output," Economics Letters, No. 114, pp. 113-19.

Bernanke, Ben S, 1983, "Irreversibility, Uncertainty and Cyclical Investment," The Quarterly Journal of Economics, Feb., 1983, Vol. 98 No. 1, 85-106.

Blagrave, P., R. Garcia-Saltos, D. Laxton, and F. Zhang, 2015, “A Simple Multivariate Filter for Estimating Potential Output," IMF working Paper, WP/15/79.

Bloom, N., 2009, “The Impact of Uncertainty Shocks,” Econometrica, 77(3), 623-685. 
Bloom, N., S. Bond, and J. Van Reenen, 2007, "Uncertainty and Investment Dynamics," The Review of Economic Studies, 74(2), 391-415.

Bluedorn, J. and D. Leigh, 2018, "In the Cycle the Trend? Evidence from the Views of International Forecasters,” IMF working Paper, WP/18/163.

Bluedorn, J. and D. Leigh, 2019, "Hysteresis in Labor Markets? Evidence from Professional Long-Term Forecasts," IMF working Paper, WP/19/114.

Bond, S., and J. V. Reenen, 2007, "Microeconometric Models of Investment and Employment." Handbook of Econometrics, 6: 4417-4498.

Bosworth, B. and S. Collins, 2008, "Accounting for Growth: Comparing China and India," Journal of Economic Perspectives, Vol. 22, No. q, pp.45-66.

Bouis, R. and R. Duval, 2011, "Raising Potential Growth after the Crisis: A Quantitative Assessment of the Potential Gains from Various Structural Reforms in OECD Area and Beyond," OECD Economics Department Working Paper, No. 835.

Bouis, R., R. Duval, and J. Eugster, 2016, "Product Market Deregulation and Growth: New Country-Industry-Level Evidence,” IMF Working Paper, WP/16/114.

Bourlès, R., G. Cette, J. Lopez, J. Mairesse, and G. Nicoletti, 2013, "Do Product Market Regulations in Upstream Sectors Curb Productivity Growth? Panel Data Evidence for OECD Countries," Review of Economics and Statistics, vol. 95, no. 5, pp. 1750-1768.

Brainard, S. and D. Cutler, 1993. "Sectoral Shifts and Cyclical Unemployment Reconsidered." Quarterly Journal of Economics, No. 108.1, pp. 219-243.

Brinca, P., J. Duarte, and M. Faria-e-Castro, 2020, "Measuring Sectoral Supply and Demand Shocks During COVID-19," COVID Economics, No. 20, pp. 54-59.

Campbell, J. and K. Kuttner, 1996, "Macroeconomic Effects of Employment Reallocation," Carnegie-Rochester Conference Series on Public Policies, No. 44, pp. 87-116.

Canon, M., M. Chen, and E. Marifian, 2013, "Labor Mismatch in the Great Recession: A Review of Indexes Using Recent U.S. Data," Federal Reserve Bank of St. Louis Review, Vol. 95, No. 3, pp. 237-71.

Celik, K., M. Kose, and F. Ohnsorge, 2020, “Subdued Potential Growth: Sources and Remedies,” World Bank Policy Research Working Paper, No. 9177.

Cerra, V. and S. Saxena, 2008, "Growth Dynamics: The Myth of Economic Recovery," American Economic Review, Vol. 98, No. 1, pp. 439-57.

Chodorow-Reich, G. and J. Wieland, 2020, "Secular Labor Reallocation and Business Cycles," Journal of Political Economy, Vol. 128, No. 6, pp. 2245-87. 
David, J. M., 2020, "Will the Covid-19 Pandemic Lead to Job Reallocation and Persistent Unemployment?” Chicago Fed Letter, No. 444.

David, S. and J. Haltiwanger, 1999, "On the Driving Forces Behind Cyclical Movements in Employment and Job Reallocation," American Economic Review, Vol. 89, No. 5, pp. 1234-58.

Deb, Pragyan, Davide Furceri, Jonathan D. Ostry and Nour Tawk, 2020, "The Economic Effects of COVID-19 Containment Measures," CEPR Discussion Paper 15087, Center for Economic and Policy Research.

de Brouwer, Gordon 1998, “Estimating Output Gaps,” Research Discussion Paper 9809, Reserve Bank of Australia.

De Vito, A, and J. P. Gomez 2020, "Estimating the COVID-19 Cash Crunch: Global Evidence and Policy." Journal of Accounting and Public Policy (2020): 106741

Doven, J. and C. Zuber, 2020, "Recessions and Potential Output: Disentangling Measurement Errors, Supply Shocks, and Hysteresis Effects," The Scandinavian Journal of Economics, No. 1, pp. 1-36.

Duarter, M. and D. Restuccia, 2010, “The Role of Structural Transformation in Aggregate Productivity," The Quarterly Journal of Economics, February, pp. 129-73.

Duval R. and C. Maisonneuve, 2010, "Long-Run Growth Scenarios for the World Economy," Journal of Policy Modeling, Vol. 32, pp. 64-80.

Eberly, J. and Wang, N., 2009, "Capital Reallocation and Growth," American Economic Review, 99(2), pp.560-66.

Fernald, J.G., 2015, "Productivity and Potential Output Before, During, and After the Great Recession," NBER Macroeconomics Annual, 29(1), pp.1-51.

Foster, L., C. Grim, and J. Haltiwanger., 2016, "Reallocation in the Great Recession: Cleansing or Not?" Journal of Labor Economics 34, No. S1: S293-S331.

Furceri, D., and A. Mourougane, 2012, "The Effect of Financial Crises on Potential Output: New Empirical Evidence from OECD Countries," Journal of Macroeconomics, Vol. 34, Iss. 3, pp. 822-32.

Furlanetto, F., and Ø. Robstad, 2019, "Immigration and the Macroeconomy: Some New Empirical Evidence," Review of Economic Dynamics, vol. 34, pp. 1-19.

Gianella, C., I. Koske, E. Rusticelli, and O. Chatal, 2008, "What Drives the NAIRU? Evidence from a Panel of OECD Countries." OECD Economic Department Working Papers 649

Goodridge, P., J. Haskel, and G. Wallis, (2018). "Accounting for the UK Productivity Puzzle: a decomposition and predictions." Economica, vol. 85(339), pp. 581-605. 
Gordon, R., 2015, "Secular Stagnation: A Supply-Side View," American Economic Review, vol. 105, no. 5, pp. 54-59.

Grant, A.L. and Chan, J.C.C., 2017, "A Bayesian Model Comparison for Trend-Cycle Decompositions of Output." Journal of Money, Credit and Banking.

Hambur, J. and K. Jenner, 2019, "Can Structural Change Account for the Low Level of NonMining Investment?”, Reserve Bank of Australia, RBA Bulletin, June 2019.

Hennessy, Christopher A., 2004, “Tobin's Q, Debt Overhang and Investment," The Journal of Finance, August 2004, Vol. 59 No. 4, 1717-1742.

International Monetary Fund, 2009, "U.S. Potential Growth in the Aftermath of the Crisis," in Selected Issues Papers for the 2009 Article IV consultations, pp. 3-15.

International Monetary Fund, 2012, “ Fiscal Policy and Employment in Advanced and Emerging Economies.” IMF Policy Paper

International Monetary Fund, 2013, “How Fast Can Brazil Grow?” Selected Issues Papers for the 2013 Article IV consultations, pp. 4-14.

International Monetary Fund, 2015, "Where Are We Headed? Perspectives on Potential Output," IMF, World Economic Outlook, April, Chapter 4.

International Monetary Fund. 2017, "Labor Market Adjustment to Shocks in Australia," in Selected Issues for the 2017 Australia Article IV consultation, pp. 4-34.

International Monetary Fund, 2018, "Labor Force Participation in Advanced Economies: Drivers and Prospects." IMF, World Economic Outlook, April, Chapter 2.

International Monetary Fund, 2020a, "The Great Lockdown: Dissecting the Economic Effects.” IMF World Economic Outlook, October, Chapter 2.

International Monetary Fund, 2020b, Regional Economic Outlook: Asia and the Pacific, IMF, October.

Jackman, R. and S. Roper, 1987, "Structural Unemployment." Oxford Bulletin of Economics and Statistics, vol.49, Iss. 1, pp. 9-36.

Jorgenson, D., M. Ho, J. Samuels, and K. Stiroh, 2007, "Industry Origins of the American Productivity Resurgence.” Economic Systems Research, Vol. 19, Iss. 3, pp. 229-52.

Kido Y., D. Muir, M. Nozaki, Y. Wong, Y. Zhou, and S. Hlatshwayo, 2020, "Why Has Investment Slowed Down in Australia," in Australia: Selected Issues, IMF Country Report No. 20/69.

King, T. and J. Morley, 2007, “In Search of The Natural Rate of Unemployment.” Journal of Monetary Economics, Vol. 54, No. 2, pp. 550-64. 
Kozlowski, J., Veldkamp, L., \& Venkateswaran, V., 2020, "Scarring Body and Mind: The Long-Term Belief-Scarring Effects of COVID-19.” Covid Economics, Vol.8.

Laeven M. and M. Valencia, 2018, “Systemic Banking Crises Revisited,” International Monetary Fund.

Lienert, A. and D. Gillmore, 2015, “The Reserve Bank's Method of Estimating Potential Output," Reserve Bank of New Zealand Analytical Note AN 2015/01.

Martin, R., T. Munyan, and B. Wilson, 2015, "Potential Output and Recessions: Are We Fooling Ourselves?” FRB International Finance Discussion Paper, No. 1145.

Meehan, L., 2014, "Structural Change and New Zealand's Productivity Performance.” New Zealand Productivity Commission Staff Working Paper.

Mitra, P., A. Hosry, G. Minasyan, M. Fischer, and G. Abajyan, 2016, “Avoiding a New Mediocre; Raising Long-Term Growth in the Middle East and Central Asia," International Monetary Fund, Middle East and Central Asia Department, Washington D.C.

Miyamoto, W., T. Nguyen, D. Sergeyev, 2018, "Government Spending Multipliers Under the Zero Lower Bound: Evidence from Japan.” American Economic Journal:

Macroeconomics, Vol. 10, No. 3, pp. 247-77.

Organisation for Economic Co-operation and Development (OECD). 2010. "The OECD Innovation Strategy: Getting a Head Start on Tomorrow," Directorate for Science, Technology and Innovation, Paris.

Ostry, J., A. Prati, and A. Spilimbergo, 2009, "Structural Reforms and Economic Performance in Advanced and Developing Economies," International Monetary Fund, Occasional Paper No. 268, Washington DC.

Ostry, J., A. Berg, and S. Kothari, 2018, "Growth-Equity Trade-offs in Structural Reforms," IMF Working Paper, WP/18/5, International Monetary Fund.

Owyang, M., V. Ramey, and S. Zubairy, 2013, “Are Government Spending Multipliers Greater During Periods of Slack? Evidence from Twentieth-Century Historical Data," American Economic Review, Vol. 103, No. 3, 129-34.

Podpiera, J., 2018, "Business Cycle in Ireland: Accounting for Open Labor Market and Multinationals" in Ireland: Selected Issues, International Monetary Fund, IMF Country Report No. 18/195.

Teulings, C. and N. Zubanov, 2014, "Is Economic Recovery a Myth? Robust estimation of impulse responses," Journal of Applied Econometrics, Vol. 29, No. 3, pp. 497-514.

Van der Merwe, M., L. Cockerell, M. Chambers, and J. Jääskelä, 2018, "Private Non-Mining Investment in Australia,” Reserve Bank of Australia, RBA Bulletin, June 2018. 